Review article

\title{
Coupling Organic and Biological Reactions with Flectroehemical Measurements for Analytical Purposes
}

\author{
by Phicip I. Elving
}

Department of Chemistry, The University of Micfigan, Ann Arbor, itichigan, $48 \mathrm{ros}$ USA:

Manuscript received May joth 1975

\section{Contents}

Surimary

Introduction

Production and utilization of potentiometric activity.

Ion-selective electrodes

Gas-sensing electrodes

Coupled enzymatic reactions

Formation of an electroactive product $-\cdots-\infty-259$

F. Cation-selective electrodes $\quad 259$

2. Anion-selective electrodes $\quad 263$

3. Gas-sensing electrodes $-v_{2},-b_{4}$

Consumption of electroactive reagent $-v_{-},-\omega_{4}$

Indirect measurement of a reaction product -265

Potential mediators

Production and utilization of polaragraphic activity $--\quad-\quad-266$

Addition of an electroactive substituent

Formation of an electroactive reaction proưuct

r. Condensation reactions

2. Periodate oxidation

3- Bromination reactions

4. Hydrolysis reactions

Formation of an electroactive complex

Utilization of catalytically produced wayes

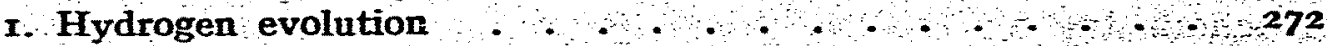

2. Oxygen exolution

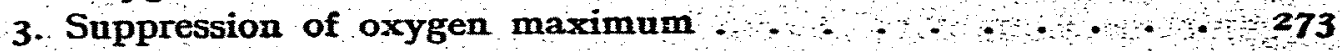

Consumption of electroactive reagent

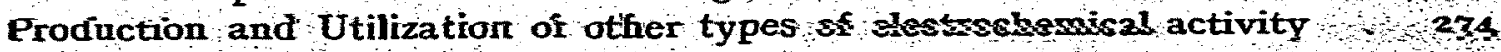

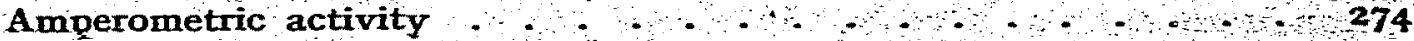

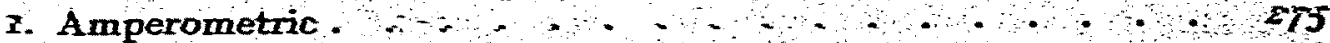

2. Amperometnc titration $=-\infty, \cdots+\infty$

Cowlometric activity

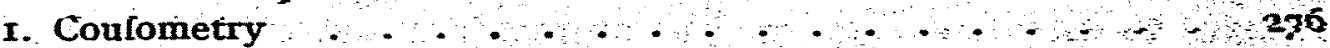

2. Coulometric titration $-2,-276$ 


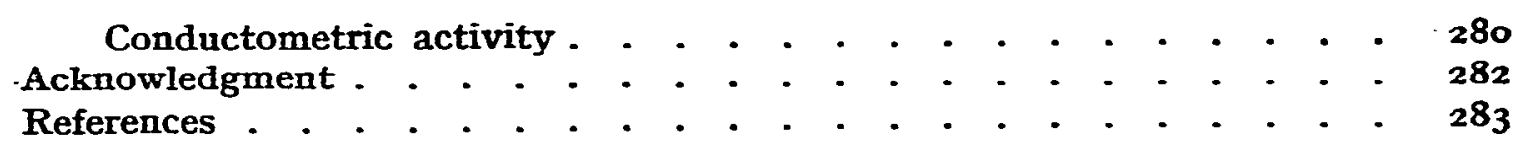
Summary

The potentialities for the determination of organic compounds of biological interest, which are inherent in coupling preliminary organic and biological reactions of nearly quantitative or highly reproducible yield with electrochemical measurements, are evident from consideration of the production of $(a)$ electroactive species for polarographic measurement and $(b)$ inorganic ions and gases for potentiometric measurement from organic compounds otherwise inert in terms of these approaches. Reactions, which are readily coupled with various polarographic techniques, include addition of an electroactive substituent, formation of an electroactive species or of electroactive complexes, and utilization of catalytically active species. In the case of potentiometry, advantage can be taken of the specificity of enzyme-catalyzed reactions, which (a) produce ammonium, cyanide and other ions, for which suitable ion-selective electrodes are available, or (b) produce or consume gases, for which selective gas-membrane electrodes are available; many of the reactionelectrode combinations so utilized can also be used for the determination of the enzyme involved. Use of potential mediators constitutes a special category for the production of potentiometric activity. Conductometry, coulometry and amperometry can also be used, following a preliminary chemical reaction, for monitoring gas chromatographic column effluents and solution compositions. In the case of all of these approaches, consumption of an electroresponsive reagent can be used to determine organic compounds by either differential concentration measurement or titration.

\section{Introüuction}

An area, which has long been important in the utilization of electrochemistry for the analytical determination of biological compounds, is the exploitation of the potentialities inherent in coupling preliminary organic reactions with electrochemical measurement, e.g., the use of mediators in potentiometric measurement and the production of polarographically active species such as aldehydes from polarographically inert compounds such as glycols. In recent years, this approach has been increasingly used in the coupling with potentiometric measurements of biological reactions for the production of electroactive species, e.g., the enzymatic conversion of organic compounds (frequently of biological origin) to inorganic ions such as ammonium and cyanide ions, for which suitable ion-selective electrodes are available. 
Another recent significant development is the use of coulometric and conductometric detectors of high sensitivity and selectivity -for monitoring the effluent of gas chromatographic columns after exhaustive oxidation or reduction of the effluent.

A general approach (long used and still available) for determining by electrochemical techniques organic compounds, which are otherwise inert in terms of a specific electrochemical technique, is the consumption of an electroresponsive reagent by the compound of interest, involving either differential concentration measurement or titration:

Although the development of selective-ion electrode activity as a result of enzymatic reaction has justly aroused wide interest and has properly been acclaimed, it should not be overlooked that this represents only one aspect, even though a most important one, of the general principle of measurement of a substance on the basis of the production or removal of an electroactive species via a chemical reaction which results in a nearly quantitative or highly reproducible relation between the original substance, whose determination is desired, and the electroactive species, which is measured.

The subsequent discussion is a summary of various ways for augmenting and enlarging the applicability of electrochemical techniques to the determination of organic compounds of biological importance by chemical manipulation prior to measurement: The discussion is primarily divided on the basis of :

a polarographic measurements, based on electrode systems; which involve electron transfer across phase boundaries with an accompanying current flow whose magnitude is generally a function of the applied potential until a limiting current value is reached,

$b$ potentiometric measurements, primarily based on ion-selective electrodes, which are electrochemical sensors, whose potentials are usually dependent in a nernstian relation on the activity of a given ion contiguous to the sensor surface with the principal component of the potential being the free-energy change associated with mass transport across a phase boundary as a result of ion-exchange, solvent extraction or some similar partition mechanism.

No attempt has been made to be exhaustive in the sense of including all reported examples of the coupling of chemical reactions with electrochemical measurement or of citing all reported studies of a given reaction-sensor combination. Rather, the purpose has been to indicate what is available in the hopes both of increasing the awareness of the analytical feasibilities of introducing chemical manipulation prior to measurement and of stimulating the development of other approaches to. the more extensive use of electrochemical methodologies and techniques for handling biological problems. 


\section{Production and utilization of potentiometric activity}

In the situation where the chemical reaction involves an electroactive reactant, reagent or product, and where there is an electrode available which can come into nernstian or quasi-nernstian equilibrium with the electroactive species, potentiometric measurement can be used. As a result of the extensive development in recent years of solid and liquid membrane electrodes, which respond to ionic species, and, more recently, of gas-sensing membrane electrodes, which respond to diffusible gases, the variety of electroactive species which can thus be measured analytically has greatly increased.

In considering the coupling of chemical reaction and potentiometric measurement, it is convenient to differentiate two situations on the basis of the contiguousness of the site of the chemical treatment relative to the electrode surface :

$a$ immediately adjacent to the electrode,

$b$ more or less remote in distance from the electrode.

Obviously, in the first case, chemical reaction generally occurs immediately prior to exposure of the electroactive species to the electrode and often involves a dynamic measurement, whereas in the second case chemical reaction usually occurs appreciably prior in time to measurement and has been completed before measurement is made.

The outstanding examples of the first case are currently those where an electrode of the dip type is covered by a suitable membrane layer of reactant or reaction catalyst such as an enzyme; examples of the second case include flowing or quiescent solutions in which the reaction involving the electroactive species occurs before the reaction mixture is monitored with an appropriate sensor electrode. In the first case, the reaction occurs in the layer immediately surrounding the sensing element of the electrode; Buck 1,2 has referred to this general situation as involving sensitized electrodes using interposed chemical reactions. The term bioprobe has been suggested by REchNITZ ${ }^{3}$ for electrodes, which have over the sensor a membrane layer containing an enzyme or enzymatic substrate.

An old but still important special example of the second case involves the use of potential mediators for measuring the equilibrium potential of redox couples which of themselves do not come into thermodynamic equilibrium with the indicating electrode rapidly enough for normal potentiometric measurement. The use of potential mediators usually involves the use of an enzyme to hasten the attainment of equilibrium.

\section{Ion-selective electrodes}

The enormous development of various types of ion-selective electrodes during the past decade is well known. Helpful reviews of these electrodes in respect to their construction, theory and utilization include 
the reviews by Bates ${ }^{4}$, Buck ${ }^{1,2,5}$ and Koryta. ${ }^{6}$ The IUPAC ${ }^{7}$ has recommended a provisional nomenclature for ion-selective electrodes.

\section{Gas-sensing electrodes}

Gas-sensing electrodes are commonly ion-selective electrodes, in which a gas-permeable membrane or an air gap separates the test solution from a thin film of an intermediate solution; the latter is either confined between the permeable membrane and the ion-responsive membrane of the electrode, or held to the electrode surface by the presence of a wetting agent (air-gap type). Interaction of the gaseous species with the intermediate solution produces a change in the latter, which is proportional to the partial pressure of the gaseous species in the test solution and which is measured by the electrode ( $c f$. example in following paragraph). The familiar oxygen electrode, often referred to as the polarographic oxygen electrode, operates on the same general mechanical configuration but utilizes a polarographic sensor, giving an amperometric response ( $c f$. subsequent section on such measurements) rather than the potentiometric response characteristic of ion-selective electrodes.

As Buck has pointed out 1 , the oldest example of a sensitized or reaction-coupled electrode is the SEVERINGHAUS $\mathrm{pCO}_{2}$ electrode involving a thin layer of soluble bicarbonate solution on the surface of a $\mathbf{p H}-$ sensing glass electrode. The chemical reaction occurring on exposure to a $\mathrm{CO}_{2}$-containing sample is the reversible conversion of $\mathrm{CO}_{2}$ to $\mathrm{H}_{2} \mathrm{CO}_{3}$ with the resulting change in $\mathrm{pH}$ being monitored and registered as $\mathrm{pCO}_{2}$. Such electrodes are now commercially available. Applications include measurement of blood gases and whole blood gas absorption. 1,2

A similar approach has been used to formulate an $\mathbf{N H}_{3}$-sensing electrode, consisting of a $\mathrm{pH}$-sensing glass electrode surrounded by a cellophane membrane containing dilute $\mathrm{NH}_{4} \mathrm{Cl}$ solution and encased in an $\mathrm{NH}_{3}$-permeable polymer membrane. ${ }^{1,2}$ Use of such an electrode is illustrated in Fig. $r$, which outlines an automated system for determining urea in $\operatorname{sera}^{8}$ ( $c f$. subsequent discussion on determination of urea).

\section{Coupled enzymatic reactions}

One of the most interesting and potentially far-reaching combinations of prior chemical reaction with electrometric measurement is in the use of enzymatic reactions to produce an electroactive species,

$$
\text { Substrate } \stackrel{\text { Enzymc }}{\longrightarrow} \text { Electroactive species }
$$

Operationally, such enzyme-sensor combinations involve interposing the enzyme system between the test solution and the species-selective electrode. This can frequently be done by immobilizing the enzyme in a polymeric or other matrix, which is mechanically placed over the sensing element of the electrode or coats the sensor as a result of being polymerized and gelled after placing of the enzyme-monomer mixture on the 


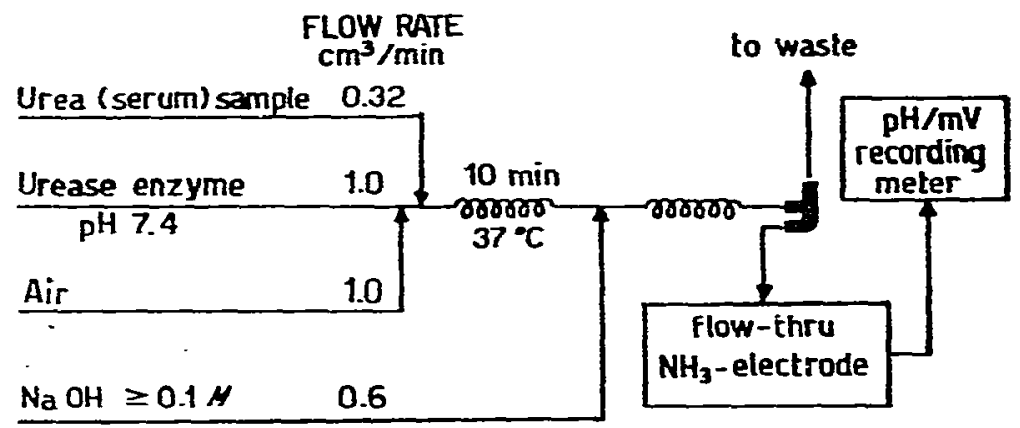

Fig. I.

Schematic diagram of an automated continuous flow analysis system for the determination of urea, using an enzymatic reaction and a gas-sensing electrode (reprinted with permission from reference 8 ).

electrode. An approach, which has been used in some instances, is to confine a thin layer of enzyme-containing solution over the electrode sensor by means of a permeable polymer membrane. The principle for assembly of such an electrode is illustrated in Fig. 2.

When such an electrode is dipped into a solution containing the appropriate substrate, the latter diffuses into the polymer layer where the enzymatic catalyst initiates the desired reaction, producting the ion to be measured, which, as a result of the increase in its activity as it is formed, diffuses to the membrane sensor of the electrode.

IUPAC " has provisionally defined such electrodes as follows: " $E n$ zyme Substrate Electrodes are sensors in which an ion-selective electrode is covered with a coating that contains an enzyme which causes the reaction of an organic or inorganic substance (substrate) to produce a species to which the clectrode responds".

It is apparent that the type of electrode just described can be turned into an electrode for monitoring an enzyme in the test solution by replacing the enzyme adjacent to the sensor by an appropriate substance.

Fig. 2.

Basic structure of an immobilized enzyme supported on a ion-selective electrode (reprinted with permission from reference 27).

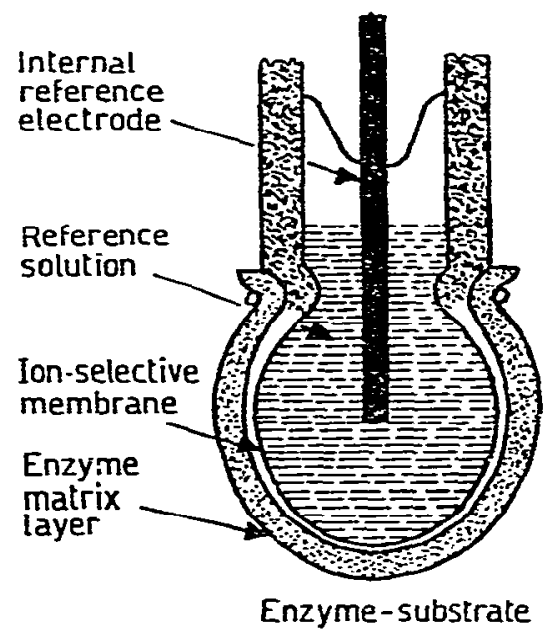


Such enzymatic approaches have the obvious general specificity of substrate-enzyme reactions and often a high concentrational sensitivity. Currently, the principal limitations to the approach seem to be :

a availability of suitable sensor electrodes,

$b$ possible interference with the sensor response by species present in biological samples other than the substrate to be measured,

$c$ the relatively short operation life of such sensitized sensor electrodes.

Factor $a$ has resulted, for example, in many of the published applications, involving $\mathrm{NH}_{4}{ }^{+}$or $\mathrm{I}^{-}$ions as the electroactive species. Factor $b$ is important, for example, because of the fact that an ammonium ion sensor also responds to the sodium and potassium ions generally present in samples of biological origin; attempts have been made to overcome this difficulty by interposing between the outer membrane layer and test solution a second membrane layer, which is permeable to the electroactive species, whose measurement is desired, but which retains, or is otherwise non-permeable to, interferring ions (or. for that matter, other possible interferences) ( $c f$. Fig. 3). Factor $s$ has probably been responsible for the failure for such electrodes to have become commercially available; REchNITz ${ }^{3}$ has suggested that many of the problems which shorten the life of enzyme-based electrodes could be overcome by making such electrodes available in kit form similar to that used for ionselective liquid membrane electrodes.

The enzyme-sensor combination was apparently first proposed in I967 by UPDIKE and HICKs 9,10 who immobilized glucose oxidase in a gelatinous polymer coating over the surface of a polarographic oxygen electrode. When the combination electrode is immersed in a solution of glucose containing dissolved oxygen, the glucose and $\mathrm{O}_{2}$ diffuse into the polymer layer where the enzyme causes the oxidation of the glucose to gluconic acid by the $\mathrm{O}_{2}$; the resulting decrease in $\mathrm{O}_{2}$ is measured by the electrode. In an earlier paper on immobilization of enzymes in polyacrylamide gels 11, HICKS and UPDIKE mention at the end that KADISH and HALL ${ }^{12}$ had used glucose oxidase with an oxygen electrode to continuously monitor blood glucose; the implication is that the KADISHHaLl approach did not involve an immobilized glucose oxidase system coupled to an oxygen electrode as in the one developed by UPDIKE and Hicks. 9,10

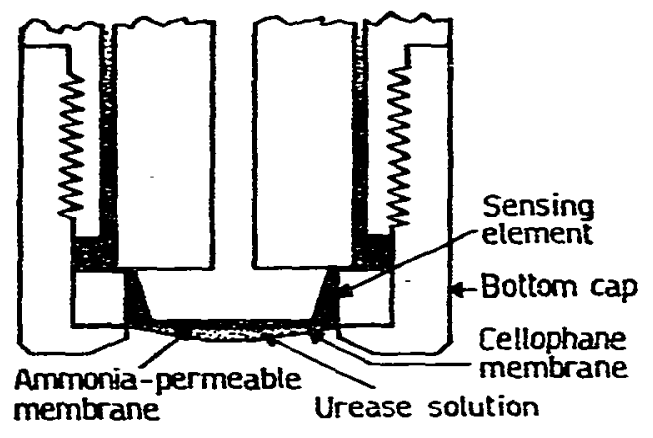

Fig. 3.

Urea sensor (gas-sensing electrode) for whole blood. showing the triple membrane design for limiting ion interferences (reprinted with permission from reference 3 ). 
Guilbault ${ }^{13}$ has reviewed the use through I967 of electrochemical methods for the measurement of enzymes and enzyme activity, as well as the principles of immobilized enzyme electrodes. ${ }^{14}$

In the rapid growing area of enzyme-selective electrode combinations employing a potentiometric response, which allows use of a $\mathrm{pH}$ meter as a measurement device, it is only proper to recognize the pioneering efforts and continuing contributions in this area of G. G. GuILBAULT of the University of New Orleans, who apparently first introduced the concept in I969 by describing an urea-responsive electrode (an ammonium ion sensor surrounded by a urease layer) ${ }^{15-17}$, and of G. A. RECHNITZ of the State University of New York at Buffalo, who first described 18 the use of an ion-selective electrode to monitor the product of an enzymatic reaction in a solution and who recently published a provocative report on membrane bioprobe electrodes ${ }^{3}$ in which the possible utilization of enzyme-based and allied reaction-coupled electrodes for biochemical and biomedical measurements is explored. Many of the methods subsequently reviewed are based on the publications of Professors Gurlbault and Rechnitz.

There is considerable literature on the immobilization of enzymes on organic carriers such as glass beads and entrapped in artificial membranes of polymerized gels such as that of acrylamide (e.g., typical references I9 to 23). The detailed preparation and characterization of lyophilized polyacrylamide enzyme gels for chemical analysis have been described by HICKS and UPDIKE. 11

Typical of the studies made on immobilized enzymes, which are pertinent to their coupling with electrochemical measurement, is that of BLAEDEL, KISSEL and Bogusiaski ${ }^{24}$ on the kinetic behavior of enzymes immobilized in gel membranes, which includes experimental studies of urease in three systems : a membrane-covered sensor electrode, a membrane separating two solutions, and a membrane immersed in a solution.

A book, which may be pertinent but which the author has not been able to inspect, deals with bioelectrodes. ${ }^{25}$

It will be apparent from the subsequent discussion that there is no limit to the analytical possiblities inherent in the coupling of enzymatic and other reactions with ion-selective electrodes except the ingenuity of the analytical chemist in solving the often difficult mechanical as well as chemical problems which may be involved. To quote REcHNITz, 26 "The monitoring and analysis of enzymes, substrates, proteins and other biological constituents has been facilitated by the use of ionand gas-sensing potentiometric membrane electrodes. Such membrane electrodes, where employed as direct probes or as components of analysis systems, provide suitable properties of sensitivity and selectivity to permit reliable analysis in various biological fluids without extensive chemical pretreatment or dialysis". 


\section{Formation of an electroactive product}

The following classification on the basis of the potentiometric electrode types used is one of convenience, since a number of the chemical reactions employed can be monitored by measurement, for example, of a cationic or gaseous product, or of an anion which reacts with a neutral product. In direct potentiometry, the reaction produces an ion for which a primary sensor is available.

\section{r. Cation-selective electrodes}

As was previously mentioned, GuILbault and Montalvo ${ }^{15-12}$ proposed the first enzyme-based sensor, based on a potentiometrically response of an electrode, which was prepared by polymerizing a gelatinous membrane (acrylamide gel 60-350 $\mu \mathrm{m}$ thick) containing the immobilized enzyme over a cationic glass electrode which was responsive to ammonium ions. When such an electrode is placed in contact with a solution of the proper $\mathrm{pH}$ containing urea, the latter diffuses into the gel layer where the enzyme catalyzes its hydrolytic decomposition:

$$
\mathrm{H}_{2} \mathrm{~N}-\mathrm{CO}-\mathrm{NH}_{2}+\mathrm{H}_{2} \mathrm{O} \stackrel{\text { Urease }}{\longrightarrow} 2 \mathrm{NH}_{3}+\mathrm{CO}_{2}
$$

Since the gel is usually prepared with a $\mathrm{pH} 7$ Tris-buffer, at which $\mathbf{p H}$ the ratio of $\left[\mathrm{NH}_{4}+\right] /\left[\mathrm{NH}_{3}\right]$ approaches 200 , the reaction of equation 2 is better replaced by the following:

$$
\mathrm{H}_{2} \mathrm{~N}-\mathrm{CO}-\mathrm{NH}_{2}+2 \mathrm{H}_{2} \mathrm{O}+\mathrm{H}+\stackrel{\text { Urease }}{\longrightarrow} 2 \mathrm{NH}_{4}++\mathrm{HCO}_{3}^{-}
$$

The ammonium ion produced at and/or diffused to the electrode surface is then sensed by the electrode in the usual glass membrane electrode manner. An electrode response curve is shown in Fig. 4 -

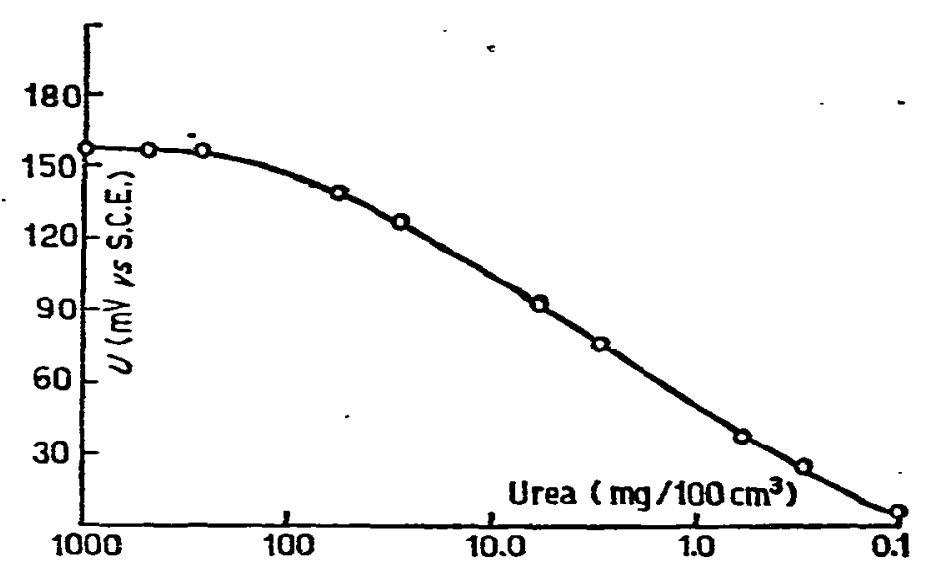

Fig. 4-

Response of urea-specific enzyme electrode with $175 \mathrm{mg}$ urease $/ \mathrm{cm}^{2}$ gel on an ammonium-ion sensor (reprinted with permission from reference 15 ). 
This approach was a logical development of the determination of urea proposed by KATZ and RECHNITZ, ${ }^{18}$ which involved complete conversion of the urea in a sample to $\mathrm{NH}_{4}^{+}$by enzyme-catalyzed hydrolysis followed by measurement of the $\mathrm{NH}_{4}+$ with a cation-sensitive glass electrode; the same approach was also proposed for the determination of urease activity. ${ }^{28,29}$

Improvements in such an urea transducer, e.g., positioning of a thin layer cellophane film over the immobilized gel electrode and use of an antibiotic complexing agent in a silicone rubber membrane to prepare a solid-type $\mathrm{NH}_{*}{ }^{+}$electrode, have been described. ${ }^{30}$ REcHNITz $^{3}$ has discussed various ways of improving the electrode configuration, e.g., Fig. 3. The method has been applied to the determination of urea in blood and urine, ${ }^{31}$ and to the determination of urease ${ }^{31,32}$ LIENADo and RECHNITZ ${ }^{8}$ have described an automated system for the determination of urea in blood and other body fluids, whose principle is illustrated in Fig. I (the final $\mathrm{pH}$ is suitably adjusted so that an $\mathrm{NH}_{3}$ gas-sensing electrode can be employed).

The same principle, as used for the urea determination, has been applied to a wide spectrum of biological compounds, for example, to the determination of $L$-amino acids, using $L$-amino acid oxidase $(L-A A O)^{33}$ :

$\mathrm{R} \cdot \mathrm{CHNH}_{3}+\cdot \mathrm{COO}^{-}+\mathrm{H}_{2} \mathrm{O}+\mathrm{O}_{2} \stackrel{L-\mathrm{AAO}}{\longrightarrow} \mathrm{R} \cdot \mathrm{CO} \cdot \mathrm{COO}^{-}+\mathrm{NH}_{4}++\mathrm{H}_{2} \overline{\mathrm{O}}_{2}$

The $\mathrm{H}_{2} \mathrm{O}_{2}$ reacts non-enzymatically with the $\alpha$-keto acid product or is destroyed by the presence of catalase. GuIlbault et al. ${ }^{16}$ described the use of such an approach to the determination of $D$ - or $L$-amino acid, asparagine, glutamine and urea, as well as of the corresponding enzymes $(D$ - and $L$-amino acid oxidases, amine oxidases, asparaginase, glutaminase and urease) ; all substrates and enzymes could be determined with a precision and accuracy of about $2.5 \%$. Analogously, specific amino acids can be determined by the use of specific amino acid deaminases with an ammonium sensor ( $c f$. Table I).

Papariello, Mukherji and Shearer ${ }^{34}$ have described the use of a glass electrode covered with an immobilized layer of penicillin $\beta$ lactamase (penicillinase) to determine penicillin in aqueous solution of pH 6.4:
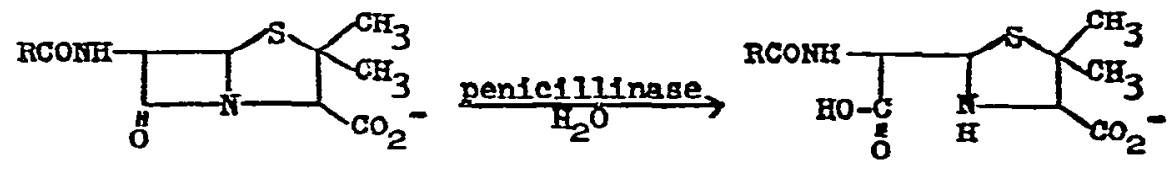

The glass electrode senses the increase in hydrogen ion activity due to the penicilloic acid. Fig. 5 shows the response curves obtained for different penicillins.

Subsequently, an improved electrode configuration was described, ${ }^{34 \mathbf{2}}$ in which penicillinase is immobilized by adsorption onto a coarse porosity fritted glass disk which is affixed to the end of a flat-surface $\mathrm{pH}$ glass 
Coupling Organic and Biological Reactions with Electrochemical etc: $26 \mathbf{1}$

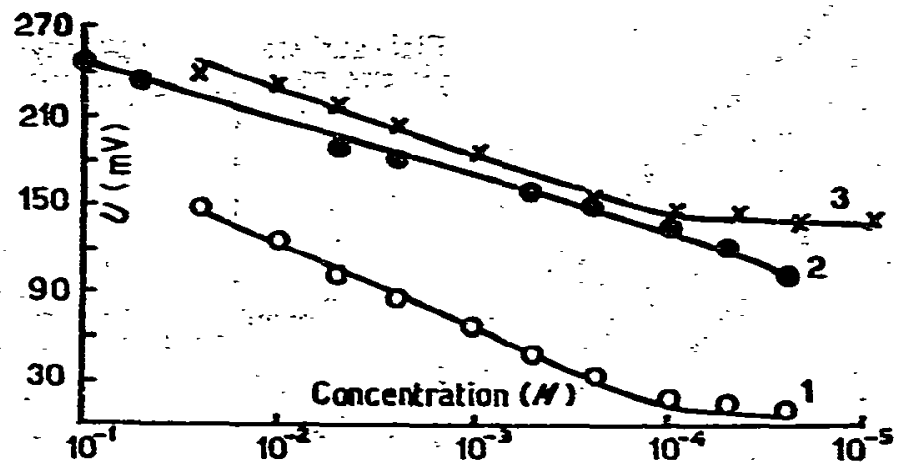

Fig. 5 .

Calibration curves for determination of different penicillins by specific electrode (enzyme-pH sensor combination) (reprinted with permission from reference 34 ) I sodium ampicillin ; 2 sodium dicloxacillin monohydrate; 3 sodium -nafcillin moriohydrate."

electrode. The system is applicable to the determination of penicillins in the 3.5 to $1,100 \mu \mathrm{g} / \mathrm{cm}^{3}$ range in such samples as penicillin fermentation broths and capsule formulations with a method precision of $\pm 3 \%$ at the $100 \mathrm{\mu g} / \mathrm{cm}^{3}$ level. A dialysis membrane electrode configuration was also described. ${ }^{342}$. The simplicity of the glass disk configuration (Fig. 6) is quite appealling and similar configuration might well be used for a variety of enzyme electrode reaction systems

Table 1 . Substrates and enzymes determined electrochemically with the (NHat) sensitive electrode $\stackrel{\text { a }}{-}$

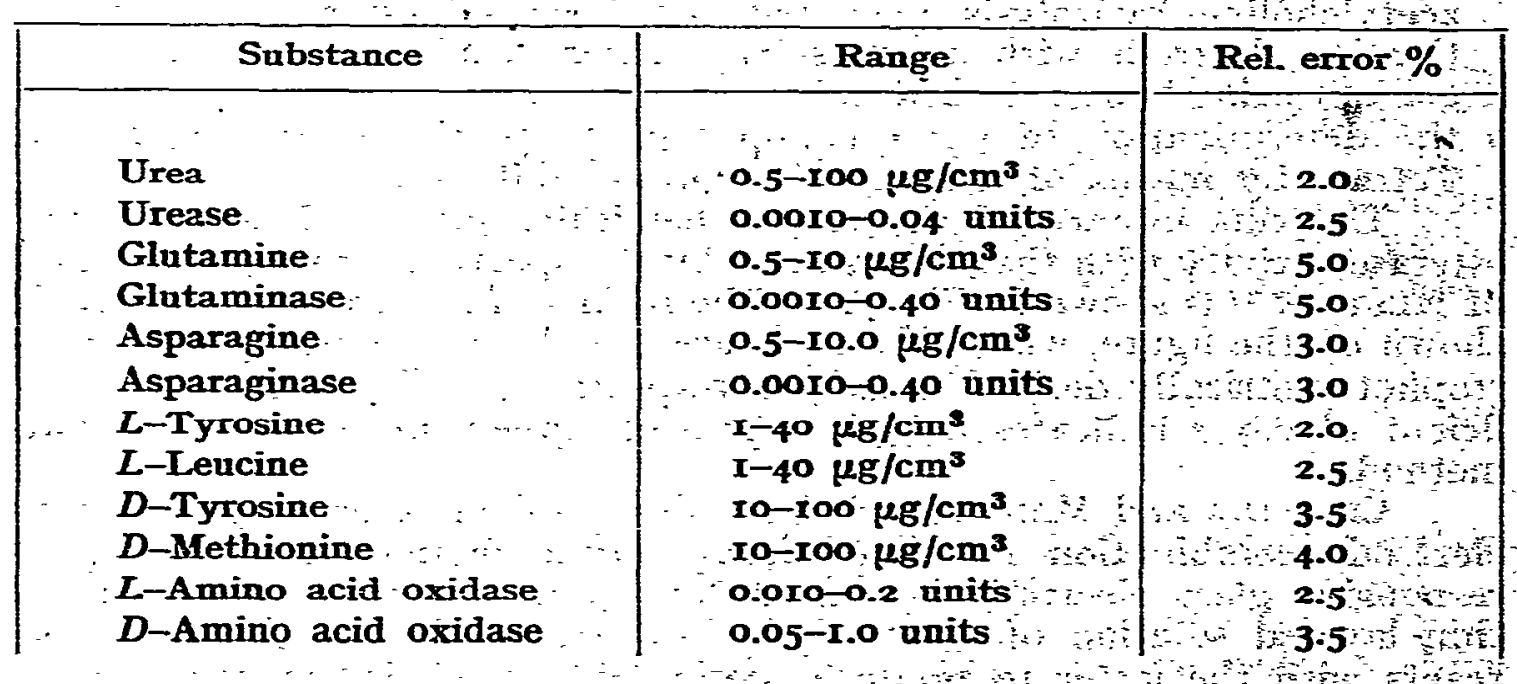

- Table is taken with permission from reference $\dot{\text { í. }}$ 
Fig- 6.

Glass disk pennicilin selective enzime electrode configuration and measurement arrangement (reprinted with permission from reference 34 a).

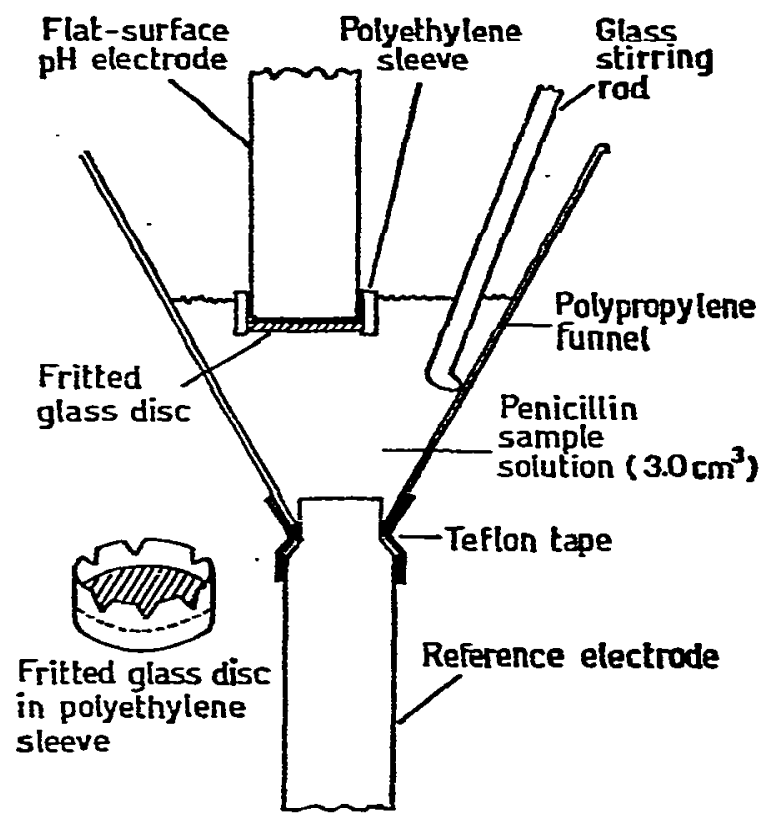

BAUM and collaborators have pioneered in the coupling of a liquid membrane ion-exchange electrode, specific for a given organic cation, with enzymatic processes involving that cation. In 1970 , the performance and utilization were described of a Corning No. 476200 acetylcholine electrode, which possesses a high selectivity for acetylcholine ion over choline and inorganic cations. 35 Applications have included:

$a$ the determination of cholinesterase activity via the monitoring of acetylcholine hydrolysis mediated by the cholinesterase, using the Corning electrode with its glass-frit barrier membrane covered by an 0.8 -mil cellophane membrane, ${ }^{36}$

$b$ the determination of the organophosphate pesticides Paraoxon and Tetram by means of their cholinesterase inhibition. ${ }^{37}$

The concordance of the electrochemically measured acetylcholinesterase activity with that determined by the spectrophotometric method of HESTRIN ${ }^{38}$ is shown in Fig. 7. ${ }^{36}$ The results of a regression analysis is shown on the figure, where $Y$ and $X$ are the electrochemically and spectrophotometrically derived activities, respectively. The correlation coefficient of 0.937 indicates a high degree of agreement between the two methods.

CROCHET and MovTalvo ${ }^{39}$ have described another enzyme-sensor electrode combination for determining serum cholinesterase. A pHresponsive glass electrode is surrounded by a membrane combining a thin-layered solution of acetylcholine substrate. Serum cholinesterase reacts with the latter to produce acetic acid, which is detected by the pH sensor. 


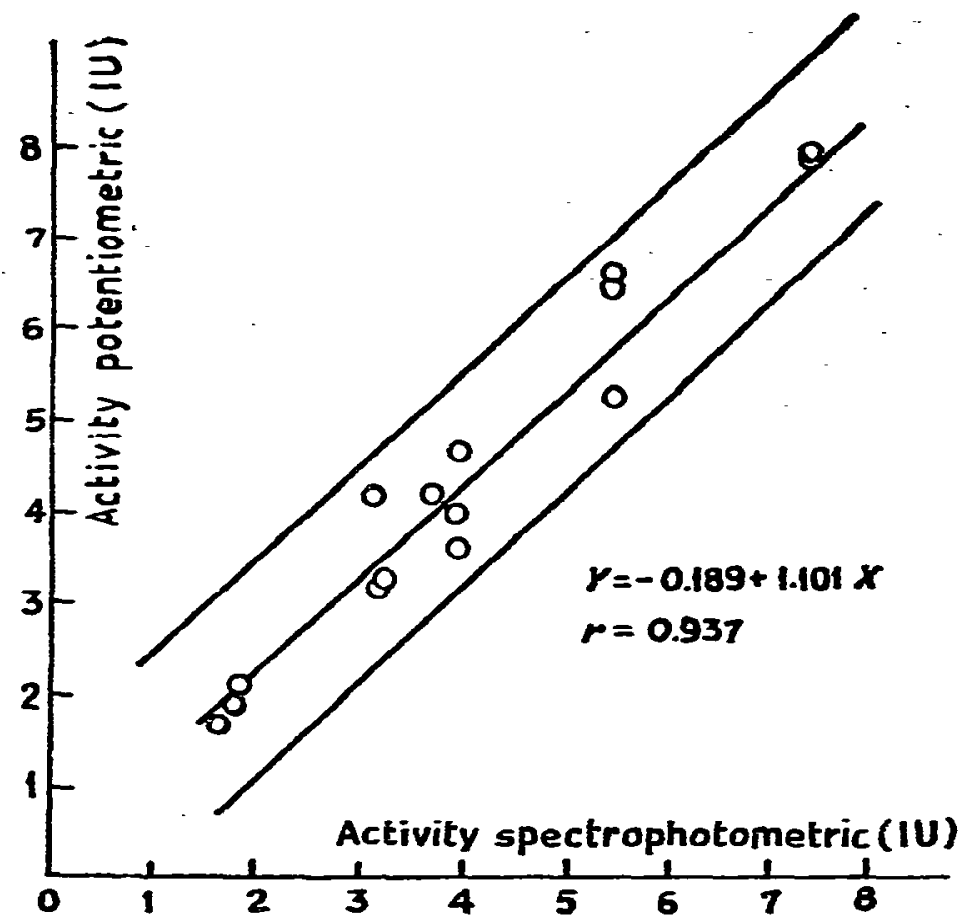

Fig. 7 .

Correlation of activity by the specific electrode method with Hestras spectrophotometric method for determination of acetylcholinesterase activity (reprinted with permission from reference $3^{6}$ ).

\section{Amion-selective electrodes}

The use of a cyanide ion-responsive membrane electrode combined with an enzyme was first reported by RECHNITZ and LLENADO. 40,41 The electrode system, which was prepared by mechanically coupling a thin membrane of polyacrylamide gel containing immobilized $\beta$-glucosidase with the polycrystalline sensing element of a solid state cyanide electrode, was used to determine amygdalin as a result of its catalyzed hydrolysis :

$$
\begin{aligned}
\mathrm{C}_{6} \mathrm{H}_{5}-\mathrm{CHCN}-\mathrm{OC}_{12} \mathrm{H}_{22} \mathrm{O}_{10} & +\mathrm{H}_{2} \mathrm{O} \stackrel{\text { B-Glucosidase }}{\longrightarrow} \mathrm{C}_{6} \mathrm{H}_{5}-\mathrm{CHO}+ \\
& +2 \mathrm{C}_{6} \mathrm{H}_{12} \mathrm{O}_{6}+\mathrm{HCN}
\end{aligned}
$$

The mechanical coupling facilitates rapid cleansing of the crystal surface and replacement of the enzyme layer when necessary.

GUILBAULT and KRAMER ${ }^{42}$ had previously described the determination of glucosidase by measuring the cyanide liberated with a silver electrode. The rate of change of potential with time after addition of 
the enzyme, $\Delta U / \Delta t$ ( $t$ in minutes), was proportional to both glucosidase and amygdalin.

The reaction of equation 6 was subsequently applied to determine $\beta$-glucosidase via reaction rate measurement, ${ }^{43}$ including use of an automated system. ${ }^{44}$ The latter paper well illustrates the options possible on utilizing reactions of adequate rate and degree of completion.

An interesting method for monitoring enzyme activity is that described for chymotrypsin, which is based on the stoichiometric $I: I$ molar reaction of the enzyme with diphenylcarbamyl fluoride, releasing one fluoride ion per molecule of active enzyme ; the $\mathrm{F}^{-}$is measured by a fluoride electrode. ${ }^{45}$

Interesting potentialities of the type described in the previous subsection involving liquid ion-exchange electrodes for organic cations are inherent in organic anion sensitive electrodes such as those described by COETZEe and Freiser ${ }^{46}$ and in the amino acid responsive electrodes described by MAtsui and Freiser. ${ }^{47}$

\section{Gas-sensing electrodes}

The principal difficulty in applying the enzyme-ammonium sensor combination to determining organic species in biological samples such as blood has been the response of the electrode used to other monovalent ions present such as $\mathrm{Na}^{+}$and $\mathrm{K}^{+}$. This difficulty has now been surmounted by the availability of a gas diffusion membrane for the determination of ammonia ( $c f$. for example, reference 48 ). Such an electrode was applied to the determination of urea (urease as enzyme) and of creatinine (creatininase as enzyme), using an automated continuous flow analysis system of the Techiricox type with a flow-through $\mathbf{N H}_{3}$ membrane electrode as the analytical sensor (Fig. I). $\mathbf{8 , 4 9}$

GUILBAULr and SHU ${ }^{50}$ have described highly specific electrode systems for determining urea and $L$-tyrosine based on coupling a layer of enzyme with a $\mathrm{CO}_{2}$ electrode. The reactions involved are

$$
\begin{gathered}
\text { Urea } \underset{L-T y r o s i n e}{\stackrel{\text { Urease }}{\longrightarrow} 2 \mathrm{NH}_{3}+\mathrm{CO}_{2}} \underset{\text { Decarboxylase }}{\longrightarrow} \text { Tyramine }+\mathrm{CO}_{2}
\end{gathered}
$$

\section{Consumption of electroactive reagent}

RECHNITZ and AIEXANDER have recently published papers, which emphasize the potentialities inherent in coupling chemical reactions with ion-selective electrodes. A silver sulfide membrane electrode can be used to follow changes in protein concentration in blood serum on the basis of measurement of the decrease in free silver ion activity after silver mercaptide formation with sulfur groups in the proteins following protein disulfide hydrolysis; applications of interest to clinical analysis and diagnostic medicine include changes in total levels and albumin/globulin 
ratios in blood serum, kinetics of protein denaturation, and the analysis of serum filtrates. ${ }^{51}$. Based on measuring the fixed-time denaturation kinetics of proteins, an automated flow system was developed for determining total sulfur-containing proteins in serum or distinguishing between individual proteins based on reactivity differences. ${ }^{52}$ The basic approach was adapted to detecting specific protein concentration changes due to immunoprecipitin formation in specific ancibody-antigen reactions, ${ }^{53}$ thus contributing an additional approach to immunoassay.

\section{Indirect measurement of a reaction product}

In this approach, which has been referred to as the coupled indicator method or reaction, the primary chemical reaction produces a species which reacts in a secondary reaction with the ion being monitored by the sensor electrode. As an example, the catalyzed oxidation of glucose by molecular oxygen ${ }^{44}$ can be cited :

$$
\beta-D-\text { Glucose }+\mathrm{H}_{2} \mathrm{O}+\mathrm{O}_{2} \underset{\text { Oxidase }}{\stackrel{\text { Glucose }}{\longrightarrow}} D \text {-Gluconic acid }+\mathrm{H}_{2} \mathrm{O}_{2}
$$

for which the indicator reaction could be

$$
\mathrm{H}_{2} \mathrm{O}_{2}+2 \mathrm{H}^{+}+2 \mathrm{I}^{-} \stackrel{\mathrm{Mo}(\mathrm{VI})}{\longrightarrow} 2 \mathrm{H}_{2} \mathrm{O}+\mathrm{I}_{2}
$$

when using an iodide sensor electrode. The same reaction scherse has been applied to the determination of glucose, 54 using peroxidase enzyme as the catalyst for reaction (ro) with a mixture of both enzymes being placed over the electrode sensing element for measurement in stationary solutions.

A similar arrangement, using a dual enzyme reaction layer over an iodide sensor, can be used to determine $L$-phenylalanine. $L$-Amino acid oxidase catalyzes the hydrolysis of the phenylalanine to produce hydrogen peroxide [equation (4)] and horseradish peroxidase catalyzes the $\mathrm{H}_{2} \mathrm{O}_{2}-\mathrm{I}-$ reaction of equation Io. ${ }^{55}$

The reaction-scheme of equations (9) and (ro) was combined with an automated analysis system based on the continuous flow technique and a novel flow-through type ion-selective membrane electrode for the automatic determination of glucose in the physiological concentration range at sampling rates of up to 70 determinations per hour for aqueous;, protein-loaded and serum samples. ${ }^{\mathbf{5 6}}$

\section{Potential mediators}

The equilibrium (standard, formal, conditional) electrode potentials reported for many redox couples, including a large number of biological interest, are based on equilibrating the redox couple of interest with another redox couple (the mediator), which is known to be electrochemically reversible and active in establishing a stable electrode potential 
under potentiometric conditions. This approach is of particular importance in the case of redox couples which do not of themselves establish a stable electrode potential. The obvious principle involved is that when a state of thermodynamic equilibrium has been attained between the active and inactive redox couples, the free energy difference will be zero and the two couples will have the same potential for the experimental conditions involved. From the resulting measured potential and the ratio of the concentrations of the oxidized and reduced forms of the couple of interest, the formal potential of the system can be calculated. Generally, specific enzymes have been used as catalysts to hasten the attainment of equilibrium between the two redox systems.

Provocative summaries of the salient factors involved in the use of mediators are provided by $C_{L A R K}{ }^{57}$ who also provides a number of important examples. Oxidation-reduction indicators such as methylene blue are frequently used as mediators. Thus, in the classical study of the succinate-fumarate couple, methylene blue was used as mediator and succinic dehydrogenase as catalyst.

A special subdivision of mediator action involves the coupling of three redox couples or systems, where redox systems $A$ and $B$ do not interact with each other at significant rate but each system reacts satisfactorily with a third system $C$. For example, quinone systems were found to mediate in the interaction between cytochrome $c$ and certain flavoproteins. 58

\section{Production and utilization of polarographic activity}

The polarographic inertness of such organic functional entities as unconjugated aliphatic hydroxyl and carbonyl groups is generally due to the unavailability of sufficient applied potential for the media and electrodes customarily employed to result in their reduction or oxidation. In aqueous media, the effective limiting potential for reduction processes at the dropping mercury electrode (D.M.E.), which has the most negative hydrogen overpotential of the usually used electrode materials (mercury, platinum, various forms of carbon), is around -2.0 to $-2.2 \mathrm{~V}$ (vs. the saturated calomel electrode, in respect to which reference electrode all potentials cited in this paper are referred unless otherwise stated) due to discharge of the usual background electrolyte cations employed. If the latter is a tetraalkyl-ammonium ion, the working potential range can be extended to about $-2.6 \mathrm{~V}$, where direct reduction of water occurs. At positive potentials in aqueous media, the limiting potential with mercury electrodes is controlled by the oxidation of mercury, being between $c a$. 0.0 or $0 . I \mathrm{~V}$ or even more negative in the presence of species forming complex or insoluble species with mercury, e.g., chloride ion, and 0.4 or $0.5 \mathrm{~V}$ in their absence. With solid non-mercury electrodes, e.g., pyrolytic graphite or glassy (vitreous) carbon, potentials as positive as ca. I.5 V may be reached; the limitation is due to oxygen evolution. In 
some non-aqueous solvents, a somewhat greater potential range may be available.

As a consequence of the limitations just outlined, an important aspect of polarographic organic analysis is the possibility of converting electrochemically inert compounds into electroactive species, usually by one of the following general procedures, which depend upon prior use of chemical reactions involving the constituent whose determination is desired. It is generally necessary that these reactions proceed with high yield, e.g., $95 \%$ or greater, and that one of the products formed be polarographically active.

The classification of reaction types is obviously more or less arbitrary, but it does offer some general basis for determining what can be done to apply chemical treatment to a given compound in order to produce polarographic activity.

\section{Addition of an electroactive substituent}

The addition of an electroactive group to an otherwise polarographically inert compound is illustrated by the conversion of benzene to dinitrobenzene by reaction of the benzene with a nitrating agent such as a nitric acid-sulfuric acid mixture. The reduction of the resulting adduct provides a method of good sensitivity since the polarographic wave or combined waves is generally the result of a twelve-electron faradaic process (6 electrons for reduction of each nitro group to the corresponding amino group).

The extensive applicability of this approach is indicated by the listing by PIETRzyK ${ }^{59}$ of papers published in 1965-67, which describe the use of nitration to produce polarographic activity. Applications include the determination of benzene in blood, liver, spleen, brain and bone, of diphenylmethane derivatives such as Palfium, Metadon and Heptalgin in organs and tissues, and of a variety of drugs and their metabolic products. ZuṂan 60 has summarized a number of procedures involving nitration, largely of benzene derivatives.

The principle of controlled nitration followed by polarographic monitoring is applicable to the determination of a wide variety of gompounds, which contain phenyl rings, but which may lack functional groups readily responsive to other methods of analysis. This approach has been described, as was just indicated, for a considerable number of drugs. For example, phenothiazine yields on nitration two polarographic waves (resulting from a total I2-electron process); which pattern is quite satisfactory for analytical purposes. ${ }^{61}$

Brooks, DE SILva and HACKMAN ${ }^{62}$ described a differential pulse polarographic assay for the determination of phenolbarbital and of diphenylhydantoin in blood, which apparently involves mononitrated rings. Similarly, DE Sriva and HACKMAN ${ }^{63}$ described a sensitive and specific assay for the determination of glibornuride (a tolysulfonyl urea hypoglycemic agent) in blood based on differential pulse polarography of the nitrated derivative; the sensitivity, using a $2 \mathrm{~cm}^{3}$ sample, is of the order of $0.05-0.10 \mu \mathrm{g} / \mathrm{cm}^{3}$ of blood. 


\section{Formation of an electroactive reaction product}

This approach differs from the preceding one in that a chemical reaction is used not to add an electroactive group to the compound but to convert an electrochemically inert functionality into one which is electroactive, accompanied at times by degradation of the compound into smaller molecules, some or all of which are electroactive. An allied approach involves chemical reaction to alter an electroactive compound at a site or sites near the electroactive functionality so as to shift the potential of oxidation or reduction of the latter in order to facilitate measurement in terms of a desired analytical objective.

A special case of the formation of an electroactive reaction product involves the conversion of the substance to be determined into an electroactive conjugate acid or base. This is exemplified by the situation that a compound, polarographically inert in acidic solution, may be converted in alkaline medium (for example, due to enolization or other tautomeric behavior) into a reducible, e.g., conjugated unsaturated, system. Many purines such as adenine are reducible only in their protonated from. ${ }^{84,65}$

\section{Condensation reactions}

The formation of an electroactive product is illustrated by the conversion of carbonyl groups, including the difficultly reducible ketonic carbonyl groups, to more easily reducible azomethine, e.g., imine, groups through reaction with ammonia or ammonia-derived compounds,

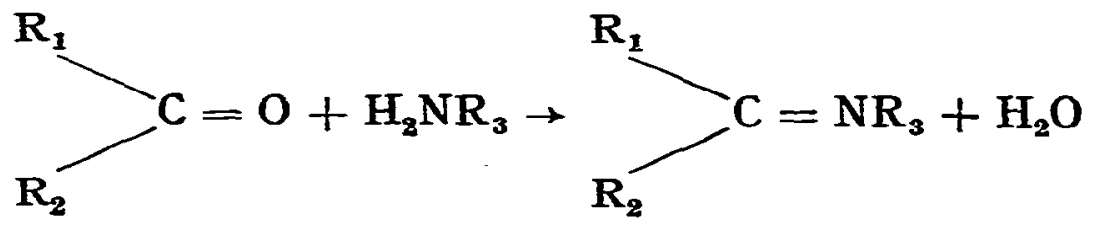

where $R_{3}$ is $H, O H, N_{2}$, alkyl, etc. Many examples of such reactions involving ammonia and primary amines have been discussed by ZUMAN and BREZINA ${ }^{60,66}$, who have also reviewed the similar condensation of carbonyl compounds to form oximes and hydrazones, including reaction with GIRARD reagents as originally developed for the determination of ketones as well as ketosteroids and of hydroxysteroids which could be oxidized to ketosteroids. Recently, the polarographic determination of carbonyl compounds after condensation with $o$-phenylenediamine has been described. 67

Nanogram quantities of carbonyl compounds in natural water and industrial wastes can be determined by converting them to the semicarbazones or other azomethine derivatives and applying twin cell potential sweep voltammetry. ${ }^{672}$. Individual carbonyl compounds can be determined down to $0.25 \mathrm{~kg} / \mathrm{liter}$ without any separation or preconcentration of the sample. 
Another example of production of an electroactive group from an inactive group involves the nitrosation of secondary amines to form nitrosamines.

\section{Periodate oxidation}

The MALAPRADE reaction involving periodate oxidation has been extensively used in the determination of compounds containing adjacent hydroxyl or similar groups, which are quantitatively oxidized by periodic acid to polarographically reducible carbonyl groups, e.g., mixtures of ethylene and propylene glycols can be analyzed by oxidizing the glycols with periodate, distilling the formaldehyde and acetaldehyde formed into a suitable solvent, and polarographically examining the re:sultant solution :

$$
\begin{aligned}
\mathrm{CH}_{2} \mathrm{OH} \cdot \mathrm{CH}_{2} \mathrm{OH} & +\mathrm{HIO}_{4} \rightarrow 2 \mathrm{HCHO}+\mathrm{HIO}_{3}+\mathrm{H}_{2} \mathrm{O} \\
\mathrm{CH}_{3} \cdot \mathrm{CH}_{2} \mathrm{OH} \cdot \mathrm{CH}_{2} \mathrm{OH}+\mathrm{HIO}_{4} & \rightarrow \mathrm{HCHO}+\mathrm{CH}_{3} \mathrm{CHO}+\mathrm{HIO}_{3}+\mathrm{H}_{2} \mathrm{O}
\end{aligned}
$$

Due to the well defined shapes and separation of the two aldehyde waves, it is only necessary to read the current at three potentials, ise.; preceding the formaldehyde wave and on the plateau of each of the two waves.

The use of chemical reaction to prepare a sample for measurement is further exemplified by analysis of mixtures of ethylene and propylene chlorohydrins via hydrolysis of the latter to the glycols and application of the procedure just outlined. ${ }^{69}$.. Mixtures of ethylene and propylene oxides have been analyzed by hydrolyzing them to chlorohydrins; further hydrolyzing the latter to the glycols, and then going through the periodate oxidation and polarographic measurement:- Glycerol has been selectively determined in fermentation residues by: polarographic measurement of the formaldehyde formed on periodate oxidation following treatment in ethanol solution with lime to remove other formaldehydeproducing compounds. ${ }^{70}$

The wide applicability of the MALAPRADE reaction in the oxidation of organic functional groups is well summarized by DRYHURST ${ }^{71}$ and by DYER. 22

\section{Bromination reactions}

Citric acid, whose measurement is important in agricultural, biochemical and medical studies, can be determined by following the modified KREBS and EGGLESTON method ${ }^{73}$ through the bromination step to convert the citric acid to pentabromoacetone and then direct po larographic measurement of the aqueous solution of the latter; the polarographic procedure avoids the usual petroleum ether extraction: oxidation-reduction treatment, and final titration procedure. The three polarographic waves observed, only one of which needs to be measured, are apparently due to dibromoacetic acid and bromoform, into which the 
pentabromoacetone is quantitatively hydrolyzed. $D$-Isocitric acid, one of the components in the KREBS tricarboxylic acid cycle, can be similarly determined after its enzymatic conversion to citric acid. ${ }^{73}$

In a bromination method of general applicability, unsaturated compounds are brominated and the resulting products are polarographed with the olefins being determined from the carbon-halogen bond fission waves which are produced ${ }^{75}$ (see also reference 60 p. I29).

\section{Hydrolysis reactions}

An example of the shift of the ease of electroactive response by chemical reaction is provided by the analysis of mixtures of maleic and fumaric acids and of their diethyl esters based on examining the wave patterns obtained before and after hydrolysis. ${ }^{76}$ Before hydrolysis, three waves are observed : a composite ill-defined wave due to both esters and two well-defined waves due to each of the acids (Fig. 8). After hydrolysis, only the latter two waves are observed and these have increased in amount equal to the respective esters originally present.

Aspartic acid can be precisely determined in rather complex samples of protein hydrolyzates by converting the aspartic acid through a simple quantitative reaction with dimethyl sulfate to an adduct which can then be readily converted to a mixture of maleic and fumaric acids for polarographic measurement. ${ }^{27}$

\section{Formation of an electroactive complex}

Organic acids of various types, e.g., carboxylic, phenolic and purine, when dissolved in pyridine, produce a one-electron diffusioncontrolled polarographic wave per acidic function, which arises from electrochemical reduction of the pyridinium species produced. ${ }^{\mathbf{7 8 , 2 9}}$ When

Fig. 8.

Polarograms of mixtures of maleic and fumaric acids, and their diethyl esters (reprinted with permission from reference 76 ). $A$ : before hydrolysis ; $B$ : after hydrolysis ; $A^{i}$ : due to a mixture of diethyl esters ; $A^{\prime \prime}$ : maleic acid ; $A^{\prime \prime \prime}$ : fumaric acid ; $B^{\prime}$ : maleic acid after hydrolysis ; $B^{\prime \prime}$ : fumaric acid after hydrolysis. All species in curve $A$ are r.oo mM.

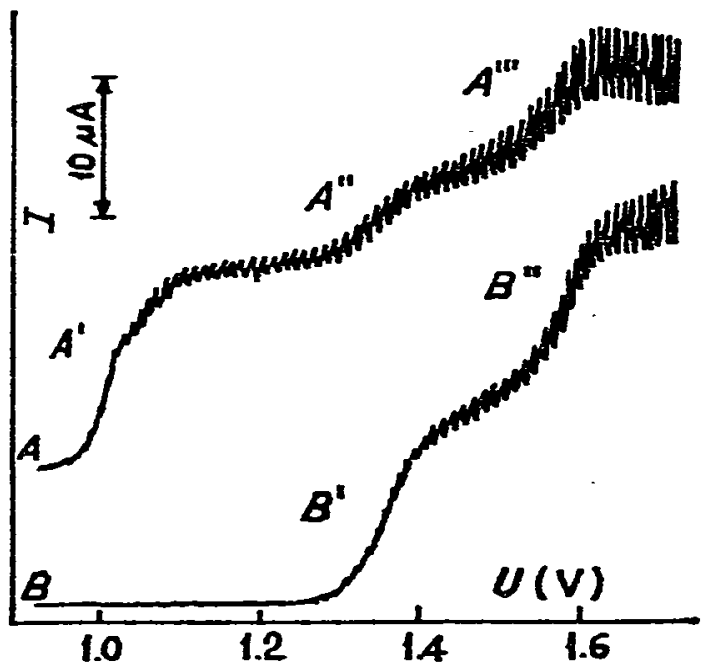


lithium perchlorate is used as background electrolyte, all acids of aqueous $\mathrm{p} K_{a}$ less than $c a .9$ produce waves of identical half-wave potential : $\left(U_{y_{2}}\right)$ When tetraethyl-ammonium perchlorate is the background electrolyte, separate but parallel correlations exist for each type: of acid between $U_{i / z}$ and aqueous $\mathrm{p} K_{a}$; a levelling effect is seen for acids of $\mathrm{p} K_{2}$, less than 3 . Mixtures of acids, depending on the background electrolyte used, can be analyzed for total acid content or, depending on type and $\mathrm{p} K_{a}$, individually.

Formation of an electroactive complex is effective in a few instances for determing organic compounds, which coordinate with metal ions, due to the organic ligand affecting the ease of reduction of the metal ion with which it is complexed, e.g., production of a new polarographic wave for: copper(II) solutions when amino compounds are present which complex the copper, e.g. reference $60 \mathrm{pp}$. I35-40.

An area, which has been insufficiently explored, is the determination of organic compounds at mercury electrodes by the use of anodic waves due to mercury oxidation, analogous to those obtained with halide ions. Thus, mercaptobenzothiazole, which gives a cathodic wave due to the catalytic evolution of hydrogen ( $c f$. next subsection), gives an anodic wave due to the formation of the mercury(I) compound 80 : A similar anodic wave is given by nicotinamide-adenine dinucleotide $\left(\mathrm{NAD}^{+}\right.$; DPN+; coenzyme I) due to formation of a mercury complex by the adenine moiety. 81

ZUMAN (reference 60 p. 99) has tabulated the functional groups which produce anodic waves at the D.M.E. as a result of their forming insoluble compounds or stable complex compounds with mercury of the electrode.

Table 2. Standard deviation associated with various concentrations of 2mercaptopyridine-N-oxide ion on pulse cathodic stripping voltammetry ${ }^{a}$

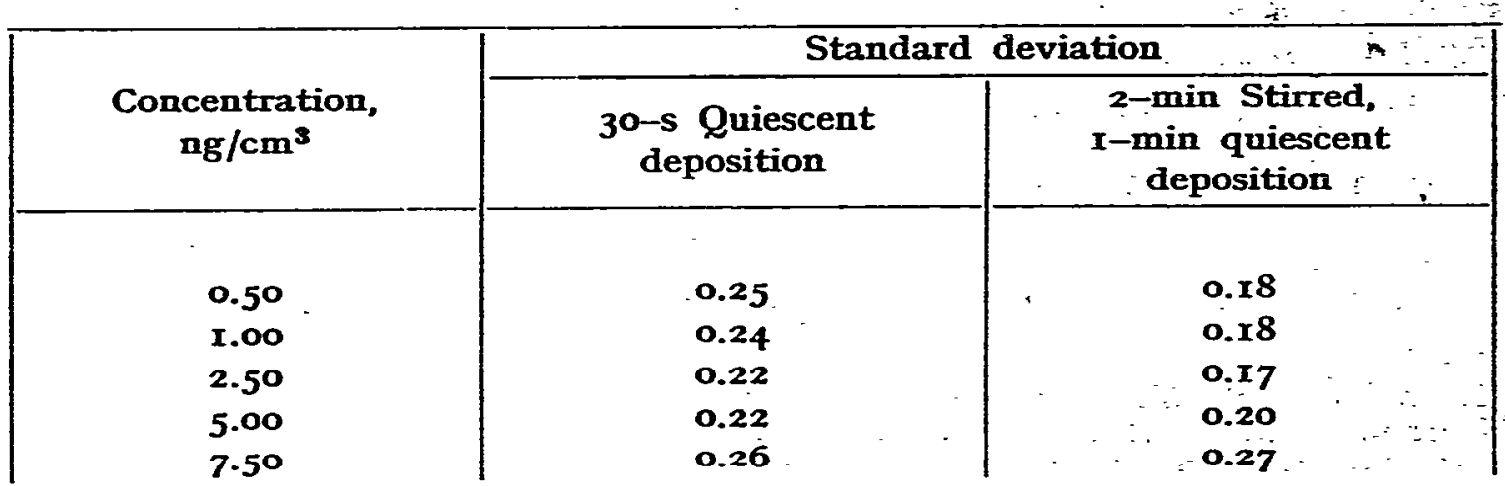

- Table is taken with permission from reference 82 . 
The range of potentialities inherent in combining chemical reactions with electrochemical measurement is well illustrated by the determination of the sodium salt of 2 -mercaptopyridine- $\mathbf{N}$-oxide by differential pulse cathodic stripping voltammetry as described by CSEJKA, NAKOS and DU BORD. ${ }^{82}$ The initial two-minute application of a potential of -0 .Io $\mathrm{V}$ to the hanging mercury drop electrode, while agitating the solution, resulted in the following deposition reaction:

$$
\mathrm{RS}^{-}+\mathrm{Hg}^{\rightarrow} \mathrm{RSHg}+\mathrm{e}^{-}
$$

After a further one-minute quiescent interval, a scan to more negative potential was initiated, producing a cathodic peak at $-0.24 \mathrm{~V}$ due to the reverse of reaction (I4). The method could be applied to solutions as dilute as $8 \times 10^{-10} M$ in the $z$-mercaptopyridine- $\mathrm{N}$-oxide ion. The type of voltammogram obtained is illustrated in Fig. 9 ; the precision obtainable is seen in Table 2. The selectivity can be made quite good by suitable chemical treatment of the test solution; appreciable amounts of halide and cyanide ions can be tolerated.

\section{Utilization of catalytically produced waves}

\section{Hydrogen evolution}

Use of the polarographic wave due to catalyzed hydrogen ion discharge has frequently been suggested for quantitative analysis since the magnitude of the wave is proportional to the $\mathrm{pH}$ of the solution and to the concentration of the catalyst. The latter class includes certain types of amino acids, protei ns,alkaloids, many nitrogen heterocycles and sulfhydryl compounds. The catalytic wave often manifests itself as a large maximum on the current-potential curve with the current being frequently many times the magnitude expected for a diffusion-controlled process. The essential mechanism involved is as follows:

$$
\begin{aligned}
\mathrm{H}^{+}+\mathrm{Cat} & \rightarrow \mathrm{CatH}^{+} \\
\mathrm{CatH} \mathrm{H}^{+}+\mathrm{e}^{-} & \rightarrow \text { Cat }+0.5 \mathrm{H}_{2}
\end{aligned}
$$

Fig. 9.

Typical pulse cathodic stripping voltammogram on a mercury electrode of ionized 2-mercaptopyridineN-oxide (concentration : 5 p.p.b.) (reprinted with permission from reference 82). $A: 30$ s quiescent deposition; $B: 2$ min stirred plus' 1 min quiescent deposition.

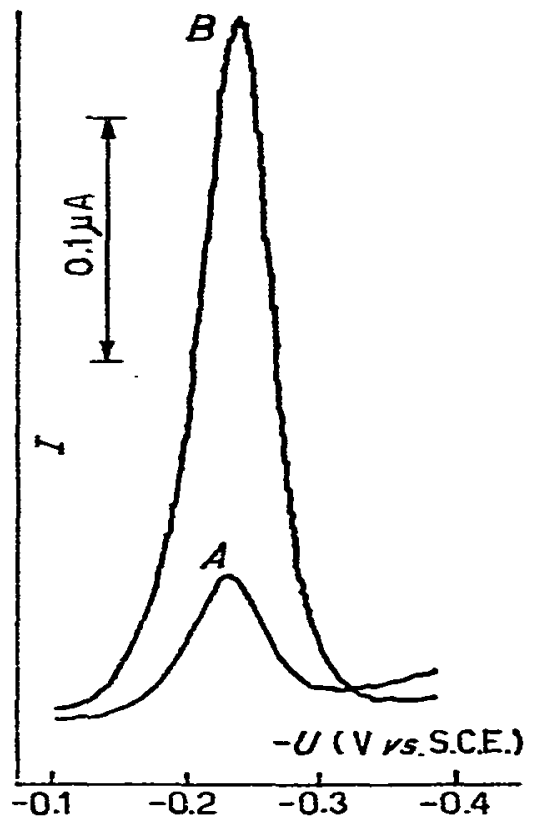


where the overpotential or activation energy for reduction of $\mathrm{CatH}^{+}$ to produce $\mathrm{H}_{2}$ is less than that for the reduction of $\mathrm{H}^{+}$itself at the mercury electrode. The catalyst compound is obviously recycled and can thus produce a reduction wave equivalent to many times its concentration.

A related type of reaction involves the production of catalytic hydrogen waves in buffered solutions of certain transition metal ions such as those of cobalt or nickel by many compounds containing bivalent sulfur as well as by a few other compounds. The classic example is the wave given by cystine and cysteine in ammonia buffer solutions containing cobaltous ion. ${ }^{83,84}$

The topic of catalytic and kinetic waves in polarography has been thoroughly reviewed by MaIRANOvskir. ${ }^{85}$ The most interesting and potentially most important example of the analytical utilization of catalytic waves has been in the controversial application to the clinical diagnosis and study of cancer first suggested by BrdičKA; MÜller, 86 RAPPOLT ${ }^{87}$ and HomolKA ${ }^{83}$ have reviewed the BRDIČKA reaction; a group of papers on the BRDrčKA reaction was also presented at a symposium. ${ }^{89}$

\section{Oxygen evolution}

Although, as just mentioned, many analytical methods have been based on the catalytic effect of the constituent to be determined in lowering the overpotential for hydrogen evolution on mercury, little has been done on the similar utilization of the oxygen overpotential due to solvent oxidation in aqueous media. The catalytic evolution of oxygen at the graphite electrode was made the basis of an analytical method, using the fact that in the presence of non-ionic surface-active agents, e.g., the polyoxyalkalene ethers such as Triton $\mathrm{X}$-Ioo, an anodic wave appears at the graphite electrode at very positive potential, ${ }^{\mathrm{o}}$ which is due to a prior adsorption of surfactant on the electrode surface, which lowers the overpotential for oxygen evolution on graphite (perhaps from water bound to the surfactant) and results in an evolution of oxygen with the concomitant desorption of the surfactant film. Since the current varies with the amount of the surfactant adsorbed, which in turn depends on the surfactant concentration in the solution, it can be used to estimate the latter (Fig. Io).

\section{Suppression of oxygen maximum}

Suppression of the oxygen maximum seen on the first oxygen reduction wave at the D.M.E. by surface-active substances has long been advocated for determining organic compounds present at trace levels. This approach would seem to be especially advantageous in the determination of surface-active substances of unknown nature, e.g., assay of the purity of refined sugar, ${ }^{91}$, where the surface-active substances are considered to be equivalent to the organic non-sugar compounds present. 
Fig. ro.

Voltammograms at a graphite electrode of $0.25 M \mathrm{~K}_{2} \mathrm{SO}_{\text {, solutions containing varying }}$ amounts of Triton X-roo (wt. \% indicated on curves) (reprinted with permission from reference 90). Polarization rate: $200 \mathrm{mV} /$ min.

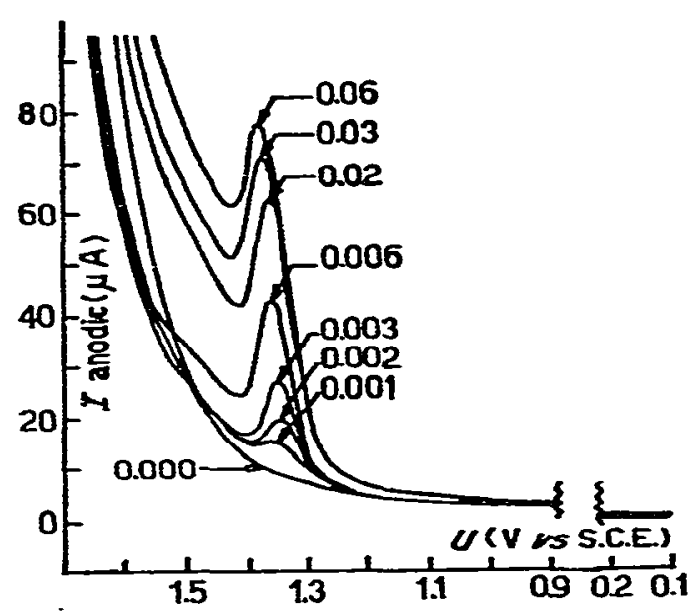

Consumption of electroactive reagent

As has been indicated, organic compounds can be determined :

$a$ by titration with a polarographically reducible or oxidizable reagent (cf. subsequent discussion of amperometric titration),

$b$ by measuring the amount of such reagent consumed in the reaction.

There is the obvious limitation that such means of -measurement are usually not specific in their applicability, except insofar as the chemical reaction used in determining the desired constituent is specific, e.g., determination of carbonyl group by measurement of sulfite consumed. Many of the reactions previously discussed can be applied with measurement not of the electroactive product but of the excess reagent, e.g. polarographic determination of excess bromine after bromination of an olefin or of excess periodate after application of the MALAPRADE reaction ; clearly, the specificity of measurement is generally less.

After the oxygen-flask combustion of fluorine-containing organic compounds, the liberated fluorine, as $F^{-}$ion, can be precipitated as $\mathrm{PbCIF}$ with the excess $\mathrm{Pb}^{2+}$ being measured by its cathodic wave or the $F^{-}$can be precipitated as $\mathrm{CaF}_{2}$ with excess calcium iodate with the free iodate thus released being determined by its polarographic reduction wave. ${ }^{92}$ It should also be possible in at least some situations to measure the fluoride ion produced potentiometrically with a specific fluoride electrode.

\section{Production and utilization of other types of electrometric activities}

\section{Amperometric activity}

Two categories of amperometric activity are important. In amperometry, the current due to the reduction or oxidation of a reactant and/or product of a chemical reaction involving the species to be de- 
termined is measured in a polarographic configuration, i.e., at an electrode upon which is imposed a potential sufficient to cause the desired reduction or oxidation involved to occur. In amperometric titration, the variation in a similar oxidation or reduction current during the course of a titration reaction is followed and is used to detect the equivalence point.

\section{Amperometry}

An amperometric method of obviously widespread potential utility is based on a combination of the enzymatic approach previously described with an appropriate polarographic electrode. For example, it may involve the determination of substrates which are oxidized by molecular oxygen in the presence of a suitable enzyme with the decrease in oxygen content of the solution being monitored amperometrically, e.g., in terms of the current flow at a platinum electrode, which is covered by a thin layer of immobilized enzyme and to which a suitable potential is applied.

In the section on potentiometric measurement, it was pointed out that the enzyme-sensor electrode combination was apparently first proposed in 1967 by UPDIKE and HrCKs, 9,10 who applied it to the measurement of glucose in terms of the response of a polarographic oxygen electrode.

Clark ${ }^{93}$ was apparently the first to propose the coupling of enzymatic reactions which produce hydrogen peroxide, such as that of subsequent equations (I7) and (I8), with a platinum sensor electrode, to which a potential is applied sufficient to oxidize or reduce the $\mathrm{H}_{2} \mathrm{O}_{2}$; the resulting current is proportional to the $\mathrm{H}_{2} \mathrm{O}_{2}$ concentration and hence to the species whose oxidation produced it. The system will function with a variety of hydrogen peroxide-generating enzymes (oxygen oxidoreductases), of which a considerable number are known, e.g. CLARK ${ }^{84}$ has listed some thirty enzymes which catalyze reactions consuming $\mathrm{O}_{2}$ and producing $\mathrm{H}_{2} \mathrm{O}_{2}$, and which can be applied to determine a large number of biologically interesting organic compounds. The broader definition of the system is described in a number of patents. ${ }^{95-99}$ The system, which was initially proposed for measuring glucose, ${ }^{93}$ bas been applied for the determination of a large number of compounds, e.g., alcohol. ${ }^{100}$

GuILBAULT, who reported the use of a plain platinum electrode as a support for enzyme electrodes, as described by CIARK, to be limited by adsorption effects in complex biological samples, claimed that use of a platinum glass with chemically bound enzymes eliminated these problems and could be used for the assay of a variety of compounds in such samples. For example, glucose or the enzyme involved can be determined on the basis of the reaction,

$$
\text { Glucose }+\mathrm{O}_{2}+\mathrm{H}_{2} \mathrm{O} \underset{\text { Oxidase }}{\stackrel{\text { Glucose }}{\longrightarrow}} \text { Gluconic acid }+\mathrm{H}_{2} \mathrm{O}_{2}
$$


using a platinum electrode covered by a thin layer of the enzyme chemically bound to polyacrylamide. At a potential of $-0.6 \mathrm{~V}$ impressed across the electrode, the oxygen consumed can be monitored in terms of the decrease in its reduction current. At an impressed potential at $+0.6 \mathrm{~V}$, the hydrogen peroxide produced can be monitored in terms of its oxidation with the resulting current being proportional to the glucose concentration. 101

Uric acid can be rapidly and selectively determined in human serum and urine without sample pretreatment such as deproteinization ${ }^{10 z}$ on the basis of the reaction,

$$
\text { Uric acid }+\mathrm{O}_{2} \stackrel{\text { Uricase }}{\longrightarrow} \text { Allantoin }+\mathrm{H}_{2} \mathrm{O}_{2}
$$

The method uses a simple platinum disk electrode covered with a thin immobilized uricase layer, to which a potential of $-0.6 \mathrm{~V}$ is applied. The agreement of the results obtained for uric acid in urine by the electrochemical and ultraviolet spectrophotometric methods is shown in Fig. II. The following regression equation is obtained by the method of least squares,

$$
\mathrm{Y}=0.97 \mathrm{X}+6.5
$$

where $\mathrm{Y}$ and $\mathrm{X}$ are the uric acid concentrations in $\mathrm{mg} \%$ measured by the enzyme electrode and spectrophotometrically, respectively. ${ }^{10 z}$

Fig. Ir.

Comparative assay for uric acid in urine (repinted with permission from reference 102). Temperature $=30^{\circ} \mathrm{C} ; 0 . \mathrm{x} M$ gly cine buffer ( $\mathrm{pH}$ 9.2). UV $=$ spectrophotometric method (decrease of urate at 293 nm) ; enzyme electrode $=$ amperometric urease-platinum electrode at $-0.6 \mathrm{~V}$ (rate method).

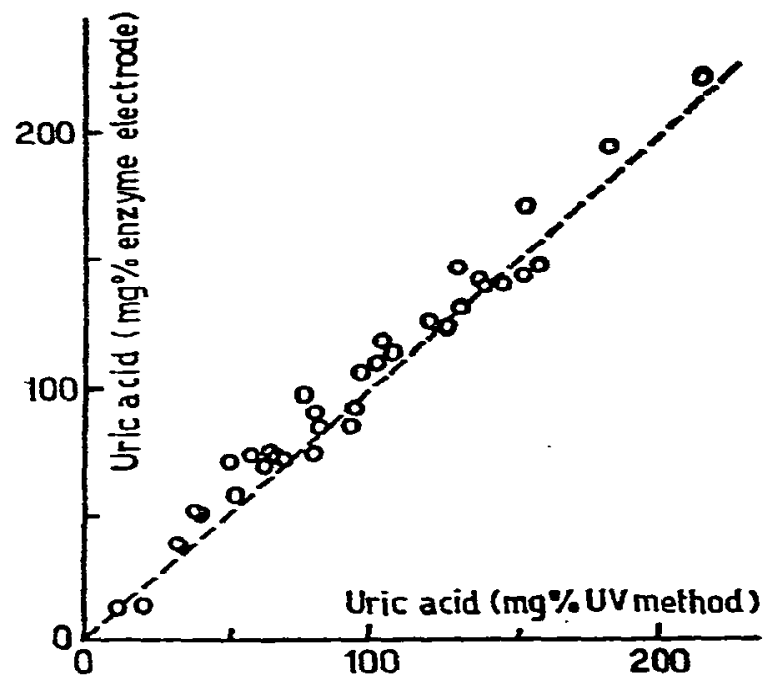

An analogous electrode system can be applied to the determination of ethanol in blood at levels of legal importance in respect to intoxication, as well as to the indirect amperometric determination of other alcohols, aldehydes and carboxylic acids. ${ }^{103}$ 


\section{Amperometric titration}

The simplicity of amperometric titration apparatus and technique makes its use quite advantageous for determining electroreducible or electrooxidizable organic compounds with the precision and accuracy attainable in properly conducted titrations, as does the possibility of polarographic determination of inert organic compounds by using electroactive titrants. In principle, amperometric titration can be applied to any reproducible reaction involving an organic compound, in: which the compound and/or reagent are electroactive and which proceeds rapidly enough. In some cases, substances which react slowly with the reagent can be determined by addition of an excess of reagent and titrimetric measurement of the unreacted reagent.

Typical examples of amperometric titration includes the titration of: a unsaturated compounds and phenols with bromate solution, which, on addition to an acidic bromide solution, generates bromine,

$b$ proteins and their degradation products through the reaction of their sulfhydryl groups with $\mathbf{A g}(\mathrm{I})$,

$c$ a wide variety of amines with tetraphenylborate, 104

d couplers such as pyrazolones or naphthols with a diazotized aromatic amine. 105

STOck provides in his book ${ }^{108}$ and annual reviews ${ }^{107}$ on amperometric titration numerous examples of the determination of biologically. significant organic compounds.

\section{Coulometric activity}

Any analytical method based on coulometry is potentially an absolute quantitative one, since the coulometric generator current integrated with regard to time is equivalent to the quantity of analyte involved if obtained under conditions of roo \% current efficiency.

Similarly to the just considered use of amperometric measurement, two categories of coulometric measurement are generally applicable.

\section{Coulometry}

It is based on selective oxidation or reduction of the desired constituent or of a related species such as a reaction product through electrolysis at a controlled electrode potential and measurement of the total current fiow. Since it is an exhaustive method, based on chemical reactivity, it often provides a precision and accuracy of analytical measurement which exceeds that possible by measurement of a physical property of a system involving the constituent.

The principles and applicability of controlled-potential electrolysis are summarized by Meites ${ }^{108}$, and BARD and SANTHANAM ${ }^{109}$ : As examples of the direct reactive coulometric determination of organic compounds by electrolysis at controlled electrode potential, PURDY ${ }^{110}$ has described the applicability of coulometry to clinical analysis and Patriarche ${ }^{111}$ has reviewed the applicability to the analysis of drugs: 
ERLANGER et al. ${ }^{112}$ developed a coulometric-amperometric method for the determination of chymotrypsin; addition of the specific inactivator, $\mathbf{N}, \mathbf{N}$-diphenylcarbamyl chloride, releases one equivalent of chloride ion for each equivalent of chymotrypsin inactivated.

\section{Coulometric titration}

The methods, using this technique, usually based on constant current electrolytic generation of titrant with time required for reaction being the factor measured, are more generally applicable to analysis, if only because of the enormous available literature on titration of organic compounds as indicated by Ashworth's huge compilation on that subject. ${ }^{113}$ However, actual applications have been largely restricted to silver precipitation reaction, e.g., for halide and sulfhydryl determination, and bromination reactions, e.g., for determination of unsaturated and phenolic compounds. Titrators based on $\mathrm{Ag}(\mathrm{I})$ generation are commercially available.

An interesting and generally useful approach involves the applicability of microcoulometric detectors (M.C.D.) to gas chromatographic column effluents consisting of organic compounds, which contain sulfur, nitrogen and halogen, and which can be converted in a suitable preliminary reaction, e.g., involving pyrolysis and/or catalytic oxidation or hydrogenation, to such species as $\mathrm{SO}_{3}^{2-}, \mathrm{S}^{2-}, \mathrm{NH}_{4}{ }^{+}$or halide ion (Table 3 ). The individual latter species is measured by a suitable coulomet-

Table 3. Coulometric and preliminary reactions for microcoulometric detectors a

\begin{tabular}{|c|c|c|}
\hline Element detected & $\begin{array}{l}\text { Coulo- } \\
\text { metric } \\
\text { reagent }\end{array}$ & Reaction \\
\hline Sulfur & & \\
\hline $\begin{array}{l}\text { Preliminary reaction } \\
\text { Coulometric reaction }\end{array}$ & $\begin{array}{l}-- \\
\mathrm{I}_{3}- \\
\mathrm{Br}_{2} \\
\mathrm{Br}_{2}\end{array}$ & $\begin{array}{l}\text { S-contg compd }+\mathrm{O}_{2} \rightarrow \mathrm{SO}_{2} \\
\mathrm{SO}_{3}^{2-}+\mathrm{I}_{3}+\mathrm{H}_{2} \mathrm{O} \rightarrow \mathrm{SO}_{2} \mathrm{O}^{2}+3 \mathrm{I}^{-}+2 \mathrm{H}^{+} \\
\mathrm{SO}_{3}+\mathrm{Br}_{2}+\mathrm{H}_{2} \mathrm{O} \rightarrow \mathrm{SO}_{2}{ }^{2}+2 \mathrm{HBr} \\
\mathrm{S}^{2}+\mathrm{Br}_{2}+2 \mathrm{H}+\rightarrow \mathrm{So}^{+}+2 \mathrm{HBr}\end{array}$ \\
\hline $\begin{array}{l}\text { Nitrogen } \\
\text { Preliminary reaction }\end{array}$ & - & $\begin{array}{l}\mathrm{N} \text {-contg compd }+\mathrm{H}_{2} \stackrel{\mathrm{Na}-\mathrm{MgO} \text { catalyx }}{\longrightarrow} \mathrm{NH}_{3} \\
\mathrm{NH}_{3}+\mathrm{H}_{2} \mathrm{O} \rightleftharpoons \mathrm{NH}_{4}+\mathrm{OH}^{-}\end{array}$ \\
\hline Coulometric reaction & $\mathbf{H}_{3} \mathbf{O}^{+}$ & $\mathrm{OH}^{-}+\mathrm{H}_{3} \mathrm{O}^{+} \rightleftharpoons 2 \mathrm{H}_{2} \mathrm{O}$ \\
\hline Chlorine & & \\
\hline $\begin{array}{l}\text { Preliminary reaction } \\
\text { Coulometric reaction }\end{array}$ & $\overline{\mathrm{Ag}^{+}}$ & $\begin{array}{l}\text { Combustion of } \mathrm{Cl} \text {-contg compd } \\
\mathrm{Cl}^{-}+\mathrm{Ag}^{+} \rightarrow \mathrm{AgCl}\end{array}$ \\
\hline
\end{tabular}

- Table is taken with permission from reference 1 x6. 
ric titration, which is monitored by an appropriate potentiometric sénsố circuit, e.g., coulometrically generated $\mathrm{Ag}^{+}$to determine $\mathrm{H}_{2} \mathrm{~S}$ produced from sulfur-containing compounds, when operating in the M:CD: reductive mode, or iodine to titrate $\mathrm{SO}_{2}$ produced when operating in the M.C.D. oxidative mode: 114,115 Such coulometric detectors are commer cially available. NATUSCH and THORPE "116 succinctly summatize this area of applicability and DAvid 11 provides a detailed critical review (cf. also reference II8).

While the microcoulometric detector systems provide means for the absolute and, in some instances, highly sensitive and specific determination of several elements, the so-called combustion or reaction coulometer is a universal gas chromatographic (G.C.) detector that responds in a similar absolute manner to all types of organic compounds including hydrocarbons. 117 In this type of coulometer (cf. Fig. I2), the column effuent is mixed with a second carrier gas stream which has passed through a continuously operating oxygen generator. The mixture passes through a reactor, in which any organic yapors present are oxidized, and then through an electrochemical oxygen sensor. The lätter responds to any decrease in oxygen concentration by initiating the generation of sufficiently more oxygen to restore the preset level The-incieased electrolysis current is an absolute measure of the amount of organic compound in the G.C. effluent. The system operates best with compounds containing only $\mathrm{C}, \mathrm{H}$ and $\mathrm{O}$, since the stoichiometry of the combustion reactions for compounds containing $N, S$ and halogens may vary somewhat.

An analogous reaction coulometer can be based on the use of exhaustive hydrogenolysis. 117

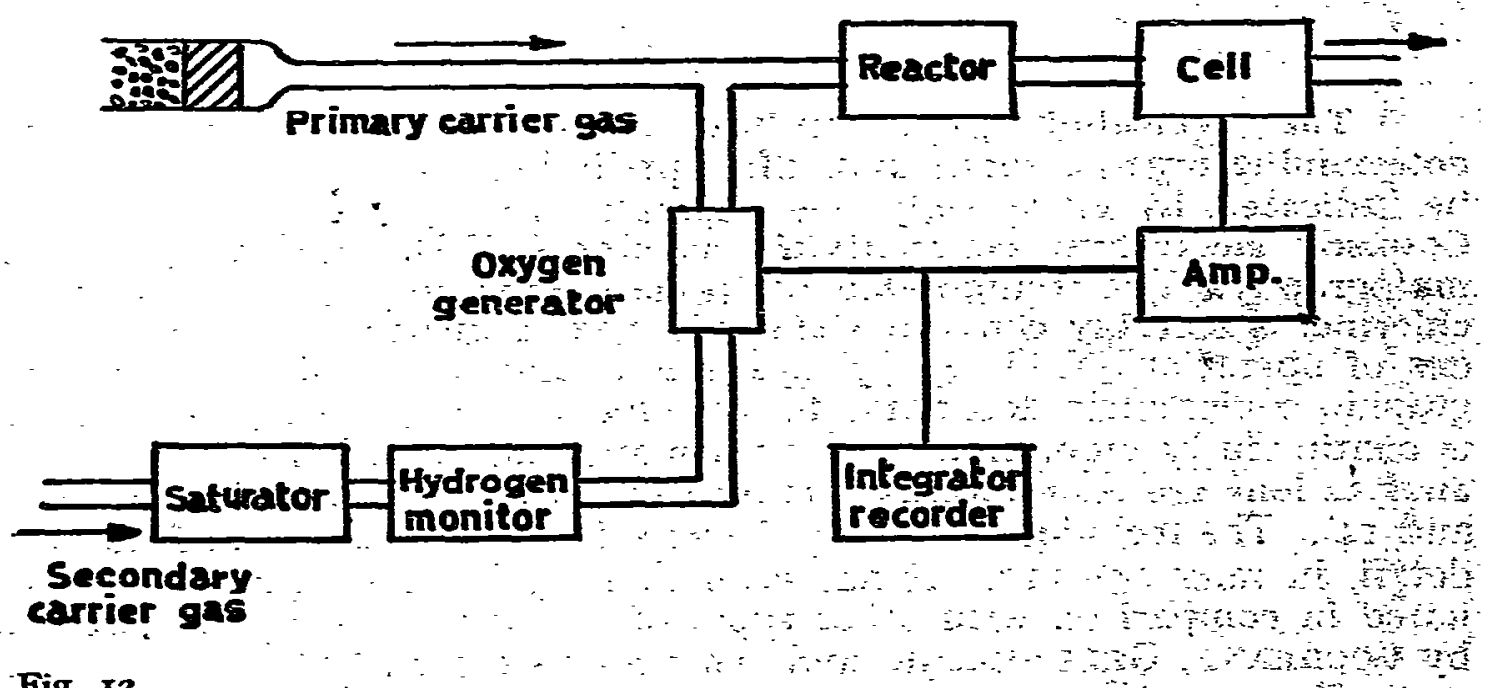

Fig. 12.

Block diagram of combustion or reaction coúlometer detector for gas chromatography based on oxygenation (reprinted - with permission from reference II7) Double lines indicate gas path and single lines indicate electrical connections 
Conductometric activity

The use of conductometric titration and of direct conductometric mearurement for analytical purposes is well known, although the applicability to organic compounds has been limited except in connection with the study of association-dissociation phenomena. However, the possible utilization for indirect determination on the basis of product measurement is promising.

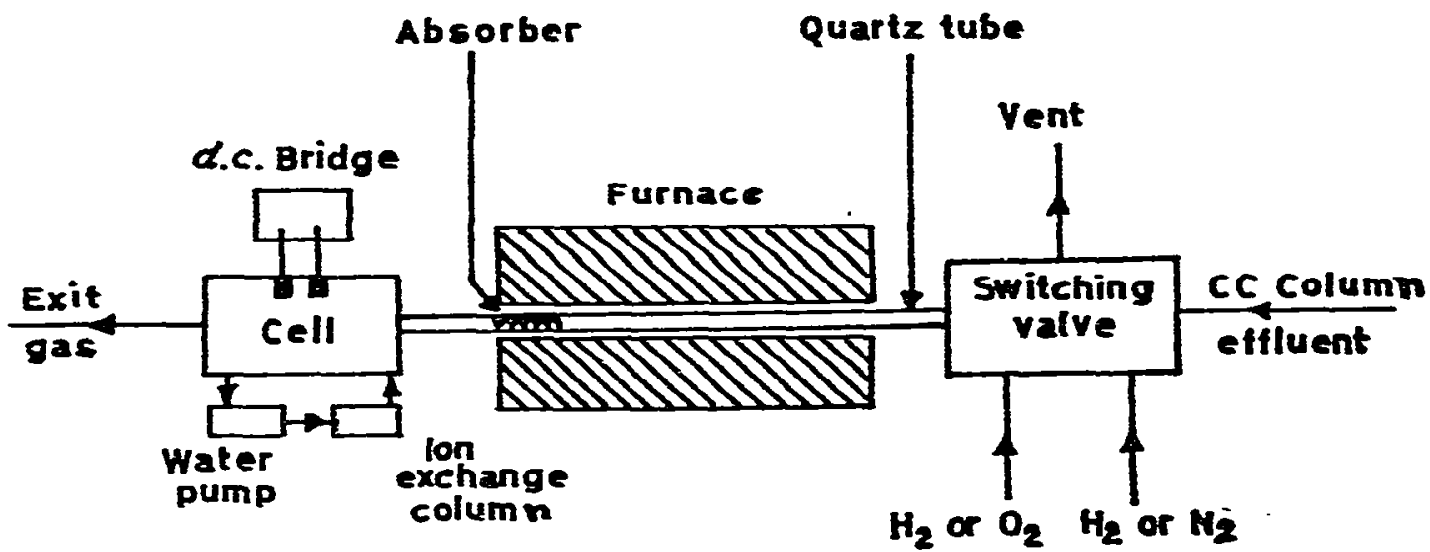

Fig. 13 .

Block diagram of electrolytic conductivity detector measurement system for gas chromatography ; details of cell shown in Fig. 14 (reprinted with permission from reference 1 rg).

The applicability of electrolytic conductometric measurement for determining organic compounds after preliminary chemical reaction can be indicated by citing only one example: the commercially available Coulson electrolytic conductivity detector (C.C.D.) used in gas chromatography. The column effluent species, containing nitrogen, sulfur or chlorine, is suitably converted via oxidative, reductive or pyrolytic modes of operation (Table 4) ( $c f$. previous consideration of gas chromatographic coulometric detectors) to an ionic product, whose conductance is continuously monitored in a d.c. conductometric cell from which the analyte ions are continuously removed by an ion-exchange loop (Fig. I3 and I4). The technique is briefly described in reference II6 and, in more detail, in reference II7. It has been thoroughly investigated and evaluated in comparison with other types of gas chromatographic detectors by Cochrane, GreENHALGH, and their collaborators. 119-124

The principal advantages of the Coulson conductivity detector are its high degrees of specificity and of sensitivity for organic compounds containing nitrogen, e.g., the nitrogen detection limit for a recently 
Coupling Organic and Biological Reactions with Electrochemical etc.

28x

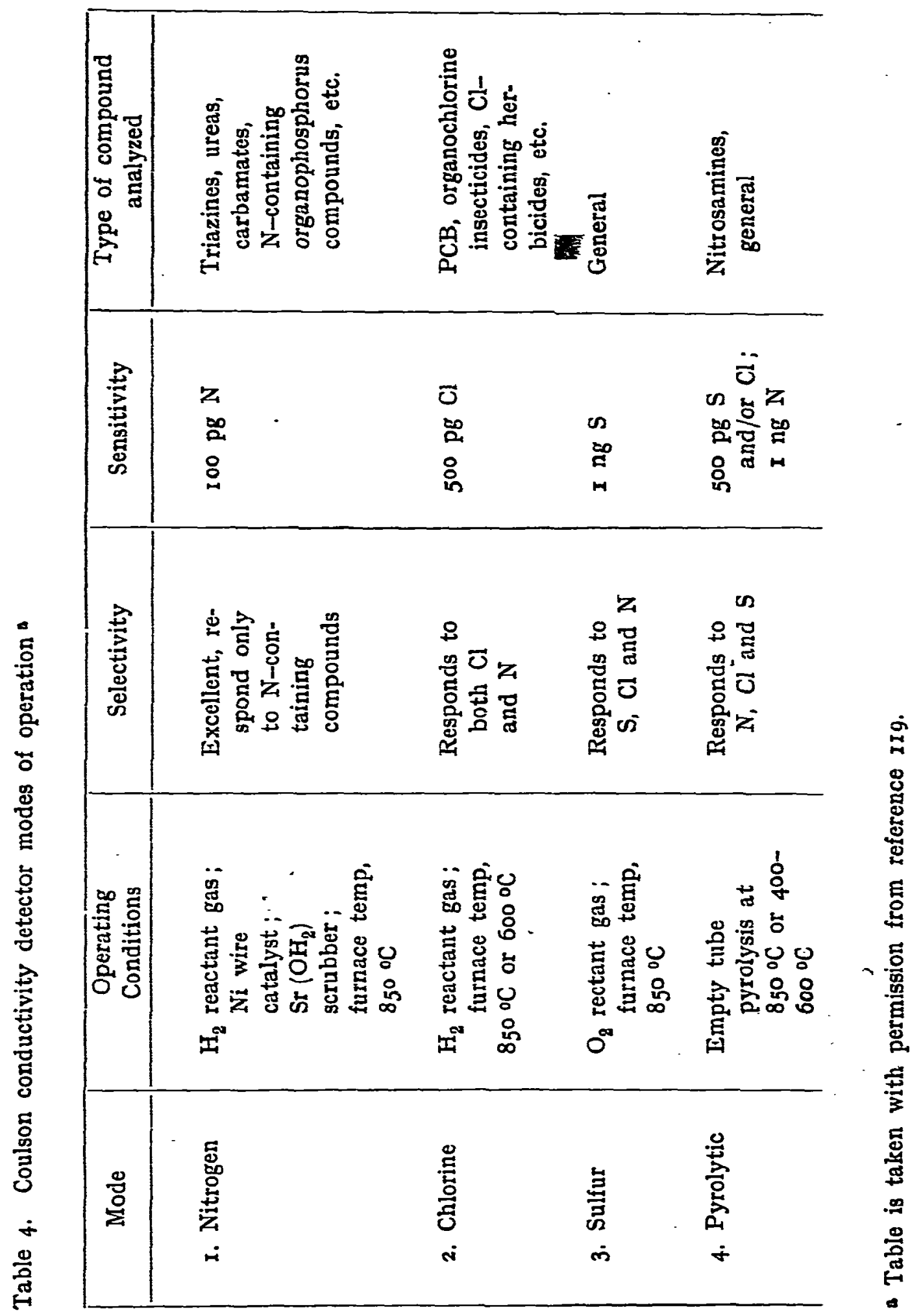


available commercial detector employing an a.c. bridge is $0.01 \mathrm{ng} .{ }^{125}$ The latter is said to allow the measurement of nitrogen, sulfur and chlorine compounds at levels well below I p.p.m. Selectivity is obtained by using different modes of operation, catalytic conditions and chemical scrubbers

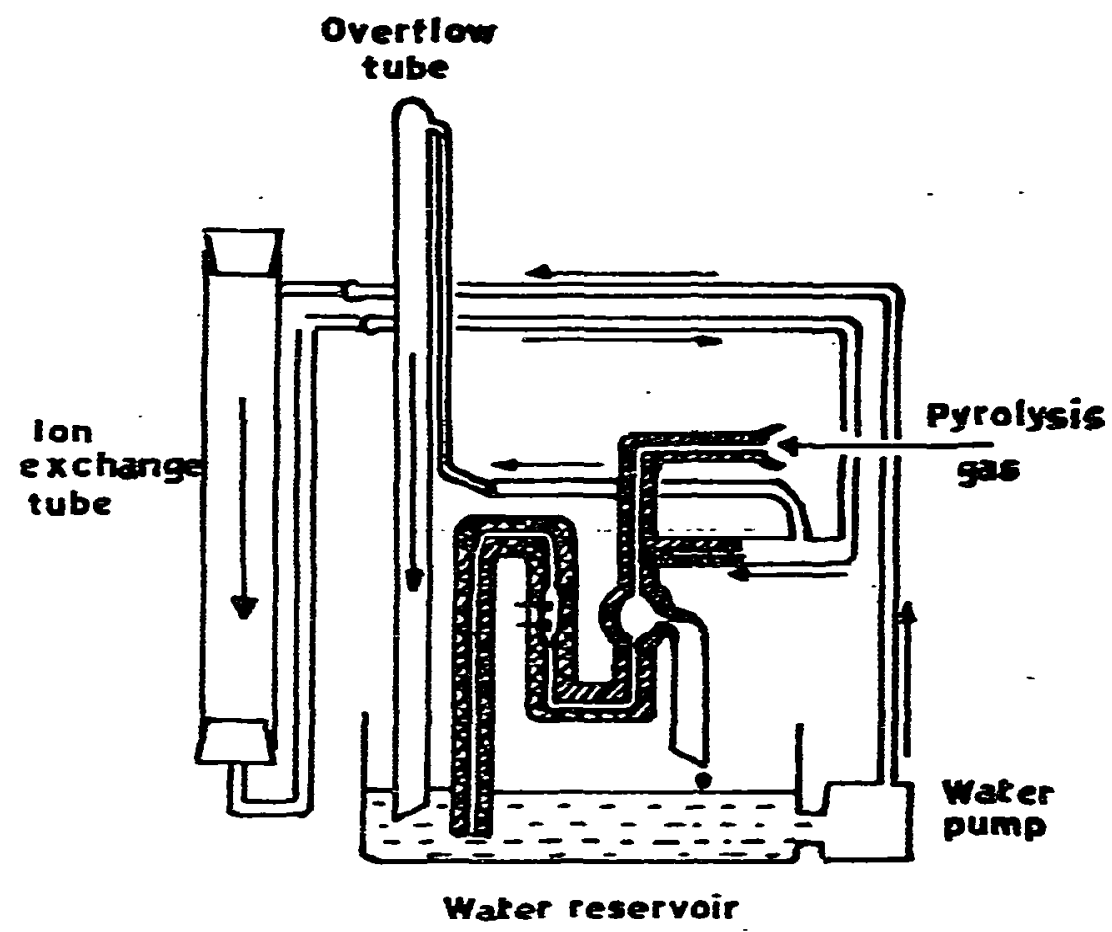

Fig. I4.

Electrolytic conductivity detector cell : structure and analytical flow path (reprinted with permission from reference 1 r9).

(Table 4). In the case of sulfur, C.C.D. is three times as sensitive as the sulfur phosphorus emission detector (S.P.E.D.) but is less specific. TyPical of the utility of C.C.D. for trace analysis is the recent discussion of its use in pesticide analysis by MCLEOD et al. ${ }^{126}$.

\section{Acknowledgment}

The author thanks the National Science Foundation, which has helped support his work on organic electrochemistry. 


\section{Rolerences}

1 R.P. Buck, Anal. Chem. 44, $278 \mathrm{R}$ (1972)

2 R.P. Buck, Anal. Chem. 46, 34 R (I974)

3 G.A. Rechnitz, Chem. Eng. News 29 (Jan. 27, 1975)

- R.G. BAtes, Determination of $p H$ : Theory and Practice, John Wiley \& Sons, New York (1973)

5 R.P. Buck, in Physical Methods of Chemistry, Part II A : Electrochemical Methods, A. WeIssberger and B.W. Rossiter, Eds., Wiley-Interscience, New York (I97I) p. 6r

6 J. Koryta, Anal. Chim. Acta, 61, 329 (1972)

? International Union of Pure and Applied Chemistry, Recommendations for Nomenclature of Ion-Selective Electrodes, Information Bulletin : Appendices on Provisional Nomenclature, Symbols, Units and Standards-Number 43. Oxford (r975)

8 R.A. Llenado and G.A. Rechnitz, Anal. Chem. 46, irog (I974)

- S.J. UPDIKE and G.P. Hicks, Nature (London) 214, 986 (1967)

10 S.J. UPDIKE and G.P. HICks, Science 158, 270 (1967)

11 G.P. Hicks and S.J. UPDike, Anal. Chem. 38, 726 (1966)

12 A.H. Kadish and D.A. HALL, Clin. Chem. 11, 869 (I965)

13 G.G. Guilbault, Anal. Chem. 40, 459 R (r968)

14 G.G. Guilbault, Biotechnol. Bioenerg. 3, 36I (1972)

15 G.G. Guilbault and J. G. Montaivo. JR., J. Amer. Chem. Soc. 91, 2164 (I969)

16 G.G. Guilbault, R.K. Smith and J.G. Montalvo, JR., Amal. Chem. 41, $600(1969)$

12 G.G. Guilbault and J.G. Montalvo, Anal. Lete. 2, 283 (1969)

18 S.A. Katz and G.A. Rechnitz, $Z$. Anal. Chem. 196, 248 (1963)

19 C.R. Lowe and P.D.G. DEAN, Affinity Chromatography, John Wiley \& Sons, New York (1974)

20 H.H. Weetall, Anal. Chem. 46, 602 A (1974)

21 O.R. Zaborsky, Immobilized Enzymes, CRC Press, Cleveland (I973)

22 L.B. Wingard, Ed., Enzyme Engineering, John Wiley \& Sons, New York (1972)

E.K. Pye and L.B. Wingard, Eds., Enzyme Enginnering, Vol. 2, Plenum Publishing Co., New York, 1974-

W.J. Blaedel, T.R. Kissel and R.C. Boguslaski, Anal. Chem. 44, 2030 (1972)

25 C.D. FERris, Introduction to Bioelectrodes, Plenum Publishing Co., New York (1974)

28 G.A. Rechivitz, American Chemical Society, Meeting in Philadelphia, April, 1975. Abstract No. 79 of Division of Analytical Chemistry

23 R.A. Durst, Amer. Sci. 59, 353 (r97 I)

23 S.A. Katz, Anal. Chem. 36, 2500 (1964)

29 S.A. Katz and J. Cowans, Biochim. Biophys. Acta 107, 605 (1965)

30 G.G. GuIlbault and G. NAGY, Anal. Chem. 45, 4I7 (1973)

31 G.G. Guilbault and E. Hrabankova, Anal. Chim. Acta 52, 287 (1970)

32 J.G. Montarvo, Jr., Anal. Chem. 51, 2093 (rg69) 
$\mathbf{3 3}$

34 I.F. CULL

Chem. 46, I955 (I974)

35 G.. BaUM, Anal. Lett. 3, ro5 (1970)

36 G. Baum, Anal. Biochem. 39, 65 (I97I)

G. Baum and F. WARd, Anal. Chem. 43, 947 (x97I)

S.G. Hestrin, J. Biol. Chem. 180, 249 (r949)

K.I. Crochet and J.G. Montalvo, Jr., Anal. Chim. Acta 66, 259 (1973)

G.A. Rechnitz and R.A. Llenado, Anal. Chem. 43, 283 (I97I)

R.A. Llenado and G.A. Rechnitz, Anal. Chem. 43, I457 (I97I)

G.G. Guirbault and D.N. Kramer, Anal. Biochem. 18, 313 (1967)

R.A. Llenado and G.A. Rechnitz, Anal. Chem. 44, 468 (1972)

R.A. Llenado and G.A. Rechnitz, Anal. Chem. 45, 826 (x973)

B.F. Errayger and R.A. SACK, Anal. Biochem. 33, 318 (1970)

C.J. Coetzee and H. Freiser, Anal. Chem. 41, irz8 (1969)

M. MatSUi and H. Freiser, Anal. Lett. 3, I6I (1970)

T.R. Gilbert and A.M. Clay, Anal. Chem. 45, I757 (1973)

H. Thompson and G.A. Rechnitz, Anal. Chem. 46, 246 (x974)

G.G. Guilbault and F.R. Shu, Anal. Chem. 44, 216r (1972)

P.WV. Alexander and G.A. Rechnitz, Anal. Chem. 46, 250 (1974)

P.W. Alexander and G.A. Rechnitz, Anal. Chem. 46, 860 (1974)

P.W. Alexander and G.A. Rechnitz, Anal. Chem. 46, 1253 (1974)

G. NAGY, L.H. von Storp and G.G. Guilbault, Anal. Chim. Acta 66, 443 (1973)

G.G. Grilbault and G. Nagy, Anal. Lett. 6, 3or (1973)

R.A. Llenado and G.A. Rechnitz, Anal. Chem. 45, 2165 (1973)

W.M. Clark, Oxidation-Reduction Potentials of Organic Systems, Williams \& Wilkins Co., Baltimore (I960)

H.R. Mahler, A.S. Fairhurst and B. Mackler, $J$. Amer. Chem. Soc. 77, I5T4 (1955)

D.J. Pietrzyk, Anal. Chem. 40, I94 R (1968); 42, I39 R (1970)

P. Zuman, Polarographic Organic Analysis, Macmillan Co., New York (1964) pp. II2-II9

A.G. Dumortier and G.J. Patriarche, Z. Anal. Chem. 264, i53 (1973)

M.A. Brooks, J.A.F. De Silva and M.R. Hackman, Anal. Chim. Acta 64,165 (1973)

J.A.F. DE Silva and M,R. HAckman, Anal. Chem. 44, II45 (1972)

B. Janik and P.J. Elving, J. Amer. Chem. Soc. 92, 235 (1970)

K.S.V. Santhanam and P.J. Elving, J. Amer. Chem. Soc. 96, 1653 (1974) M. Brezina and P. ZuMan, Polarography in Medicine, Biochemistry and Pharmacy, Interscience Publishers, New York (1958)

J. VeliseK and J. DAVIDEK, Chem. Listy 67, 513 (1973)

B.K. Afghan, A.V. Kulkarni and J.F. Ryan, Anal. Chem. 47, 488 (I975)

B. Warschowsky and P.J. Elving, Ind. Eng. Chem., Anal. Ed. 18, 253 (I946)

IV.A. Cannon, Anal. Chem. 22, 928 (r950) 
Coupling Organic and Biological Reactions with Electrochemical etc. $\quad 285$

P.J. Elving, B. : Warshowsky, E. Shoemaker and J: Margolit, Anál. Chem. 20, 25 (1948)

G. DRymurst, Periodate Oxidation of Diol and Other Functional Groups, Pergamon Press, Oxford (I970)

J.R. Dyer, in Methods of Biochemical Analysis, Vol. 3, D. GLICK, Ed., Interscience Publishers, New York (1956), Pp. III-I52

C.A. Hargreaves, M.D. Abrahams and H.B. Vickery, Anal. Chem. 23, 467 (195I)

P.J. Elving and R.E. Van Atta, Anal. Chem. 26, 295 (1954)

A.V. Ryabov and G.D. Panova, Dokl. Akad. Nauk S.S.S.R. 99, 547 (1954)

P.J. Elving, A.J. Martin and I. Rosenthal, Anal. Chem. 25, ro82 (I953)

B. WarshowsKy and M.W. Rice, Anal. Chem. 20, 34I (1948)

K. Tsuji and P.J. Elving, Anal. Chem. 41, 286 (1969)

K. Tsuji and P.J. Elving, Anal. Chem. 41, 57 I (1969)

C.V. Francis, Anal. Chem. 21, 1238 (1949)

C.O. Schmakel, K.S.V. Santhanam and P.J. Elving, J. Amer. Chem. Soc. 97, 5083 (1975)

D.A. Csejka, S.T. Nakos and E.W. Du Bord, Anal. Chem. 47, 322 (1975)

D.D. Gilbert, Anal. Chem. 41; I567 (1969)

M. Brezina and V. Gultjoj, Collect. Czech. Chem. Commun. 28, i8x (1963) S.G. Marranoviskir, Catalytic and Kinetic Waves in Polarography, Plenum Press, New York (1968)

C.H. Müller, Clin. Chem. 11, 270 (1965)

R. Rappolt, in Polarography r964, G.J. Hrlls, Ed., Interscience Publishers, New York (1966) pp. 977-983

J. HомоцкA, in Methods of Biochemical Analysis, Vol. 19, D. Grick, Ed., Interscience Publishers, New York (197x) PP. 435-555

H. Berg., Ed., Elektrochemische Methoden und Prinzipien in der MolecularBiologie, Akademie-Verlag, Berlin (rg66) pp. 423-484

P.J. Elving and D.L. Smith, in Microchemical Teckniques, N.D. CheroNis, Ed., John Wiley \& Sons, New York (1962) pp. 829-842

I. Vavruch, Anal. Chem. 22, 930 (1950)

Y.A. Gawargious, A. Besada and B.N. Faltaoos, Anal. Chem. 47, 502 (1975)

L.C. Clark, JR., in Septic Shock in Man, S.G. Hersey, R.M. Del-Guerico and R. McConn, Eds., Little Brown \& Co., Boston (197I) p. 75

L.L. Clark, Jr., in Enzyme Engineering, L.B. Wingard, Ed., John Wiley \& Sons, New York (1972) pp. 377-94

L.C. Clark, JR., U.S. Patent No. 3,539,455 (Nov, 1o, I970)

L.C. Clark, Jr., Canadian Patent No. 866,759 (Mar. 23, 197I)

L.C. Clark, J.R., Jap. Letters Patent 6ro,20x (Nov. II, 1970)

L.C. Clark, JR., Brit. Patent No. I, 167,317 (Oct. 15, 1969)

L.C. Clark, JR., Brit. Patent No. I, I69,140 (Oct. 29, 1969)

L.C. ClaRK, JR., Biotechnol. Bioenerg. 3, I7O (1972)

G.G. Guilbault and G.J. Lubrano, Anal. Chim. Acta 60, 254 (1972)

M. Nanjo and G.G. Guilbault, Anal. Chem. 46, r769 (1974)

M. Nanjo and G.G. Guilbault, Anal. Chim. Acta 75, r69 (1975)

E. Smith, L.F. Worrei and J.E. Sinsheimer, Anal. Chem. 35, 58 (1963) 
105 R.M. Elofson and P.A. Mecherly, Anal. Chem. 21, 565 (1949)

106 J. STock, Amperometric Titrations, Interscience Publishers, New York (1965)

107 J.T. Stock, Anal. Chem. 46, I R (r974)

108 L.M. MeITEs, in Physical Methods of Chemistry, Part II A : Electrochemical Methods, A. Weissberger and B.W. Rossiter, Eds., Wiley-Interscience, New York (r97x) p. 645

109 A.J. BARD and K.S.V. SANThanam, in Electroanalytical Chemistry, A.J. Bard, Ed., Marcel Dekker, New York (1970), Vol. 15, p. 215

110 W.C. Purdy, Z. Anal. Chem. 243, I7 (1968)

111 G. Patriarche, Sci. Pharm., Proc. 2, 67 (1966)

112 B.F. Erlanger, S.N. Buxbaum, R.A. Sack and A.G. Cooper, Arat. Biochem. 19, 542 (1967)

113 M.R.F. AsmworrH, Titrimetric Organic Analysis, Parts I and II, Interscience Publishers, New York (1964-65)

11 L.D. Wallace, D.W. Kohlenberger, R.J. Joyce, R.T. Moore, M.E. RidDLE and J.A. MCNulty, Anal. Chem. 42, $3^{8} 7$ (1970)

115 W.W. Marsh, Anal. Lett. 3, 341 (I970)

116 D.F.S. NAtusCh and T.M. Thorpe, Anal. Chem. 45, Irgo A (I973)

117 D.J. David, Gas Chromatographic Detectors, Wiley-Interscience, New York (I974) p. I94

118 D.A. Leathard and B.C. ShurLock, Identification Techniques in Gas Chromatography, Wiley-Interscience, New York (1970) p. 178

119 W.P. Cochrane and R. GReENhalgh, Evaluation and Comparison of Specific G.C. Detectors for the Analysis of Pesticide Residues, 3rd Annual Symposium on Recent Advances in the Analytical Chemistry of Pollutants, Athens, Georgia, U.S.A. (May 1973)

120 W.P. CochRANe and B.P. Wilsoy, $J$. Chromatogr. 63, 365 (I97I)

121 R. Greentalgh and W.P. Cochrane, J. Chromatogr. 70, 37 (1972)

122 W.P. Cochrane, B.P. Wilson and R. Greenhalgh, J. Chromatogy. 75, 207 (1973)

123 W.P. Cochrane and R. Greenhalgh, Int. J. Environ. Anal. Chem. 3, I99 (I974)

124 R. Greenhalgh and W.P. Cochrave, Int. J. Environ. Anal. Chem. 3, 213 (r974)

125 Chemistry in Britain II, Ad. I4 (March, I975)

126 H.A. McLeod, A.G. Butterfield, D. Lewis, W.E.J. Philitips and D.E. Cofins, Anal. Chem. 47, 674 (r975) 